\title{
LA REVISIÓN JUDICIAL DE LAS DECISIONES REGULATORIAS: UNA MIRADA INSTITUCIONAL*
}

\author{
Javier Tapia y Luis Cordero
}

Universidad de Chile

\begin{abstract}
RESUMEN: Este trabajo sostiene que la forma y alcance de la revisión judicial dependen centralmente de la interrelación existente entre dos variables: el carácter especializado o generalista del revisor, y el ámbito que le es conferido a éste para decidir. Si el revisor es
\end{abstract}

JAVIER TAPIA. Doctor en derecho por University College London. Ministro Titular del Tribunal de Defensa de la Libre Competencia de Chile (TDLC). Profesor en la Escuela de Postgrado de la Facultad de Derecho de la Universidad de Chile. Email: jtapia02@gmail.com.

Luis Cordero. Doctor en derecho por la Universidad de Lleida. Profesor de derecho administrativo e investigador senior del Centro de Regulación y Competencia (RegCom) en la Facultad de Derecho de la Universidad de Chile. Email: lcordero@, derecho.uchile.cl.

* Los autores quieren señalar: "Las visiones expresadas en este trabajo son estrictamente personales y no comprometen necesariamente las de las organizaciones a las que pertenecemos o las personas que en ellas trabajan. Versiones preliminares de este trabajo fueron presentadas en el $4^{\circ}$ Encuentro Anual de la Sociedad Chilena de Políticas Públicas, Valparaíso, Chile (enero 2013); en el VIII Congreso Iberoamericano de Regulación Económica y Servicios Públicos, organizado por la Asociación Iberoamericana de Estudios de Regulación (ASIER), La Serena, Chile (noviembre 2013); y en Perspectivas Comparadas de Justicia Administrativa, CIDE, Ciudad de México (enero 2014). Agradecemos a los participantes de esos foros por sus comentarios. Asimismo, agradecemos especialmente los aportes de Jaime Arancibia, Javier Barnés, Alejandro Romero, Álvaro Vives y los dos árbitros anónimos de Estudios Públicos. Muchos aciertos de este trabajo son suyos; los errores, completamente nuestros (aunque cada uno se los adjudica al otro y lo culpa de haberlos causado)". 
generalista, es probable que tenga un incentivo a ser deferente con la Administración, por lo que en principio el ámbito de revisión no debiera permitirle ir más allá de las cuestiones de derecho, pues de lo contrario el resultado podría resultar dañino para los objetivos que el sistema regulatorio persigue. Por el contrario, si el revisor es especializado, tiene escasos incentivos a ser deferente con la Administración y no debiese ser restringido en su ámbito de posibilidades, pues se perderían los beneficios de la especialización. Así, los autores postulan que sólo cuando ambas variables institucionales están intrínsecamente vinculadas (esto es, que el estándar de revisión esté diseñado "a la medida" de las características institucionales del revisor) el sistema institucional puede operar de una manera eficiente en un marco de legitimidad. Esta tesis es ilustrada acudiendo a la normativa de libre competencia y medioambiental chilena, donde la combinación de las variables institucionales no ha sido la adecuada.

Palabras Clave: diseño institucional, decisiones regulatorias, revisión judicial, recursos, expertise, libre competencia, medio ambiente. RECIBIDO: mayo 2015; ACEPTADO: julio 2015.

\section{JUDICIAL REVIEW OF REGULATORY DECISIONS: AN INSTITUTIONAL APPROACH}

ABSTRACT: This article argues that the method and length of judicial review depend primarily upon the interaction of two variables. The first one is whether the reviewer is specialised or generalist. The second variable is the scope of the review. If the reviewer is generalist, it will probably have an incentive to be deferent with the Administration. Then, in principle, the scope of the review should only extend to questions of law, because a greater scope of review may result in damage to the objectives of the regulatory system. By contrast, if the reviewer is specialised, incentives to be deferent are scarce. In this case, the scope of the review should not be restricted, in order to not reduce the benefits of specialisation. The authors hold that the institutional system can operate efficiently and with legitimacy only when both variables are fundamentally linked - this is, when the scope of review is designed taking into account the institutional characteristics of the reviewer. This thesis is illustrated with the cases of Chilean competition law and environmental law, two areas where the variables have been mixed defectively.

Keywords: institutional design, regulatory decisions, judicial review, legal actions, expertise, antitrust, environmental law.

RECEIVED: May 2015; ACCEPTED: July 2015. 


\section{INTRODUCCIÓN}

na parte fundamental de cualquier sistema administrativo-regula-
torio es la existencia de un mecanismo de escrutinio o control de las decisiones primarias adoptadas por funcionarios $\mathrm{u}$ organismos de la administración del Estado, ${ }^{1}$ ya sean pertenecientes al poder ejecutivo o de carácter independiente, ${ }^{2}$ por parte del poder judicial. ${ }^{3}$ A esto se le

${ }^{1}$ Con el propósito de universalizar las expresiones, en el presente trabajo utilizamos como sinónimas las expresiones "organismos de la administración del Estado", "organismos administrativos" y "agencias". La referencia específica a "agencias independientes" se hace en estos términos.

2 Sobre el calificativo de "independiente" de la agencias, véase la nota 45 y el texto principal al cual ésta acompaña.

3 En el derecho contemporáneo, esto es una manifestación de la llamada "tutela judicial", garantía esencial de un estado de derecho (véase, en este sentido, E. García de Enterría, La lucha contra las inmunidades del poder en el derecho administrativo, $3^{\text {a }}$ ed. (Madrid: Civitas, 1983), y Democracia, jueces y control de la administración, $6^{\mathrm{a}}$ ed. (Madrid: Civitas, 2014); y J. González Pérez, El derecho a la tutela jurisdiccional, $3^{\mathrm{a}}$ ed. (Madrid: Civitas, 2001). En Chile, el Tribunal Constitucional ha señalado que: “(...) si bien puede resultar lícito que los órganos fiscalizadores puedan, previo al proceso judicial y en el ámbito administrativo, determinar la existencia de una infracción y la cuantía de una multa, la sanción no puede estimarse como cierta e irrevocable para el ordenamiento jurídico sino una vez que no haya sido reclamada o que, habiéndolo sido, tal reclamo haya sido resuelto en sede jurisdiccional e independiente. Así lo consagra nuestro sistema al permitir que se recurra de las respectivas decisiones administrativas ante los tribunales, cuestión que no sólo está consagrada a nivel legal, sino que también, con mayor jerarquía, en la propia Constitución Política (artículo 38, inciso segundo)" (STC rol 792-07, C. 16). Con todo, la terminología no siempre es clara y depende de cada jurisdicción. Considérese, por ejemplo, la expresión "juez". En el derecho norteamericano, no obstante la Constitución establece la separación de poderes de manera expresa (su artículo I trata del poder legislativo, el artículo II sobre poder ejecutivo y el artículo III sobre poder judicial), la adjudicación de algunas materias contenciosas (contested matters) es asignada en primera instancia a organismos que no caen en el artículo III, sino en el artículo I (llamados "article I tribunals"), tales como las cortes de quiebras y las agencias que pertenecen al poder ejecutivo (véase, a este respecto, James E. Pfander, "Article I Tribunals, Article III Courts and the Judicial Power of the United States", Harvard. Law Review 118 (2004)). Con todo, la Corte Suprema de Estados Unidos ha reconocido que el Congreso puede conferir poderes judiciales a tales organismos sólo en la medida que sus decisiones sean revisadas por cortes del artículo III: American Insurance Co. v Canter (1828) 1 Pet 511, 7 L Ed 242. Como ha mostrado J. C. Ferrada ("Los tribunales que ejercen la justicia administrativa en el derecho chileno", en Litigación pública, editado por J. Arancibia, J.I. Martínez \& A. Romero (Santiago: Thomson Reuters, 2011), 119-150), en Chile existe una 
denomina tradicionalmente "revisión judicial". ${ }^{4}$ Quien esté a cargo de diseñar tal mecanismo de revisión (en última instancia, el legislador) enfrentará uno de los problemas centrales y quizás más complejos del derecho administrativo moderno: definir la relación más adecuada entre el órgano que revisa y aquél que adopta la decisión. Desde la perspectiva institucional, ésta no es una cuestión trivial ni simple. ${ }^{5}$ El diseño institucional no es neutro, ${ }^{6}$ sino que resulta determinante tanto para la

situación similar a la del derecho estadounidense, producto de una "construcción fragmentada, asistemática e incoherente" de la justicia administrativa (ibídem, 119). En el derecho inglés, dado que no hay una distinción constitucional entre un poder judicial y no-judicial, no existe prohibición de conferir poderes judiciales a instituciones más allá de las cortes. De aquí la distinción entre court y tribunal (más sobre esta distinción, ver nota 15). Con todo, las categorías amplias de "poder ejecutivo" y "agencia independiente", de un lado, y "poder judicial", de otro, dan un indicio relativamente claro a qué nos estamos refiriendo.

${ }^{4}$ Por ejemplo, H. W. R. Wade, Administrative Law, $1^{\circ}$ ed. (Oxford: Clarendon Press, 1961); Guy Braibant, Le Droit Administratif Français (París: Dalloz, 1984); E. García de Enterría y T.R. Fernández, Curso de derecho administrativo, T.II, $15^{\text {a }}$ ed. (Madrid: Civitas, 2011). Todos vinculan la revisión judicial a su rol tradicional de control de legalidad de las decisiones o acciones administrativas, incluido en ellos el control de la arbitrariedad de las decisiones. No obstante, como veremos, el rol de la revisión es esencialmente variable.

${ }^{5}$ De hecho, ésta no es una cuestión nueva en el derecho administrativo, sino que subyace a buena parte de la discusión del siglo XIX y principios del XX relativa a la existencia de tribunales especiales para juzgar los actos de la Administración. Esto explica, por ejemplo, el diseño institucional francés impuesto tras la Revolución Francesa, que vio en los jueces especiales una garantía adecuada de control de las decisiones de los organismos administrativos, llegando a la conocida cita — proveniente de la Revolución — según la cual “juzgar a la Administración es también administrar”. Del mismo modo, la famosa crítica británica de Dicey al modelo francés descansaba en la idea de que la existencia de un derecho y tribunales especiales para juzgar actos de la Administración constituía un privilegio inadmisible para el rule of law (en su concepción tradicional). Finalmente, en el caso del derecho alemán, el debate acerca de los tribunales especiales en la segunda parte del siglo XIX se asoció a la existencia de jueces que fuesen capaces de controlar las decisiones de la Administración cuando se afectaban derechos. Al igual que el francés, dicho sistema también terminó consagrando un modelo institucional de tribunales especiales, pero al interior del poder judicial. Para esta evolución institucional de especialidad del derecho administrativo y la necesidad de jurisdicción especializada, véase Elisabeth Zoller, Introduction to Public Law (Leiden: Martinus Nijhoff Publishers, 2010).

${ }^{6}$ N. Komesar, Imperfect Alternatives: Choosing Institutions in Law, Economics and Public Policy (Chicago: University of Chicago Press, 1997); R. Thaler y C. Sunstein, Nudge: Improving Decisions about Health, Wealth, and Happiness (New Haven, CT: Yale University Press, 2008). 
forma como para el alcance de la revisión judicial; aspectos que, a su vez, tienen una incidencia importante en las acciones que adoptará el órgano decisor primario.

La tesis central de este trabajo es que, en una perspectiva contemporánea (no clásica) ${ }^{7}$ de control judicial, de entre una multiplicidad de variables institucionales que deben ser consideradas al momento de planificar e implementar un determinado diseño para el sistema jurídico en un área en particular, la forma y alcance de la revisión judicial dependen centralmente de la interrelación existente entre dos de ellas. La primera es el carácter especializado o generalista del revisor respecto de la decisión de la agencia administrativa de que se trate. Para efectos de este trabajo entenderemos por jurisdicción generalista la existencia de un tribunal con competencia civil, ya sea del fuero común o bien un sistema de tribunales contenciosos administrativos dentro del poder judicial. En cambio, al referirnos a jurisdicción especializada estamos haciendo alusión a un tribunal con competencia específica en una determinada materia, al margen de las estructuras habituales del poder judicial (esto es, sin jueces de carrera), y cuya integración es mixta, es decir, con jueces con formación legal y jueces de formación técnica. ${ }^{8}$

La segunda variable se refiere al ámbito que le es conferido al revisor para decidir; esto es, si la revisión será amplia (si abarcará cuestiones de hecho, de derecho y eventualmente de política pública) o si será restringida (por ejemplo, sólo a cuestiones de derecho). ${ }^{9}$ Mientras la primera variable es de carácter orgánico, ${ }^{10}$ la segunda es sustantiva. Si bien ya la definición de cada una de ellas, por separado, implica resolver importantes dilemas (trade-offs) y problemas específicos, más importante es que las respuestas a las preguntas por la naturaleza del organismo revisor y por su ámbito de revisión debiesen estar intrínsecamente vinculadas.

\footnotetext{
${ }^{7}$ Véase nota 4 .
}

${ }^{8}$ Estamos conscientes que la distinción (basada, como se observa, en un doble aspecto: jurisdiccional y subjetivo) puede eventualmente generar vacíos. Sin embargo, es lo suficientemente comprensiva, entendible y aplicable a la mayoría de los casos como para ser de utilidad en el análisis de este trabajo. Con todo, más adelante la precisamos con mayor detalle. En un sentido similar define Peter Cane, Administrative Tribunals and Adjudication (Oxford: Hart Publishing, 2009), 91.

${ }^{9}$ Véase nota 69 y el texto principal al que ella acompaña.

${ }^{10}$ En la sección 2.1.1. explicamos que existen otras dimensiones orgánicas del diseño, pero cuya importancia relativa es menor a la mencionada en el texto central. 
Esta vinculación consiste en que el estándar de revisión debiera ser diseñado "a la medida" de las características institucionales de dicho órgano, atendidos los incentivos que generan tales características.

Así, si el organismo de revisión es generalista y carece de expertise, es altamente probable que tenga un incentivo a ser deferente con la Administración, al menos respecto de cuestiones de hecho y, posiblemente, también de política pública. Por tanto, en principio el estándar de revisión no debiera permitirle ir más allá de las cuestiones de derecho, como una forma de restringir la "tentación" de desviarse de dicha deferencia, pues, dado su carácter generalista, el resultado podría resultar dañino para los objetivos que el sistema regulatorio persigue. ${ }^{11}$ La situación es exactamente la contraria en el caso de un órgano revisor especializado en un área determinada. Éste tiene escasos incentivos a ser deferente con la Administración, pues su propio conocimiento (ya sea acumulado en el tiempo o adquirido por conocimientos en una determinada ciencia o arte) y la justificación tras su creación le permiten examinar con confianza no sólo el derecho, sino también las cuestiones de hecho y de política pública involucradas. Por tanto, si este organismo es restringido por el estándar, no parece que hubiera existido razón alguna para crear tal organismo en primer lugar, pues se perderían los beneficios de la especialización. ${ }^{12}$

Sólo cuando ambas variables institucionales están intrínsecamente vinculadas, el sistema institucional puede operar de una manera eficiente en un marco de legitimidad. Para estos efectos, entendemos por eficiencia del sistema el hecho que las controversias sean resueltas de una forma rápida, con decisiones adecuadas al tipo de materia de que se trate y que los incentivos creados por el sistema no conlleven a que la(s) etapa(s) de revisión sea(n) sobre o sub utilizada(s). A su vez, la legitimidad implica que las decisiones adoptadas sean aceptadas como válidas por el general

${ }^{11}$ Una de las posibilidades es lo que C. Sunstein \& A. Vermeule ("Interpretation and institutions", Michigan Law Review 101, 2003: 885-951), en página 949, denominan la "trampa cognitiva": la demanda de los especialistas relativa a que los jueces generalistas debieran decidir casos como especialistas, no observando las posibilidades de que emerjan de esta situación resultados mucho peores dada la emulación.

${ }^{12}$ Como expondremos, varios de los temores que tradicionalmente justifican restringir el estándar a ser aplicado por organismos especializados tienen que ver precisamente con este incentivo (esto es, con el temor a que la Administración se transforme en un mero "compilador de hechos"). 
de la comunidad. Ambas características son piezas fundamentales dentro del marco de lo que se conoce como "buena regulación". ${ }^{13}$

Nuestro trabajo viene a llenar un vacío existente en la literatura relativa a analizar la revisión judicial, la cual no ha relacionado de manera adecuada ambas variables institucionales. Por el contrario, los análisis normalmente las consideran por separado. Una parte de la literatura ha enfocado (desmedidamente) sus esfuerzos en la perspectiva orgánica, centrada paradigmáticamente en la revisión de las decisiones administrativas adoptadas en un contexto de una disputa entre el Estado y un particular, a requerimiento del ciudadano afectado por dicha decisión (sea un individuo, una corporación o un grupo), lo que suele conocerse bajo el nombre de "contencioso administrativo"14 o "adjudicación administrativa" $"$. Una variante de esta rama se enfoca en la división de

${ }^{13}$ Ver R. Baldwin, M. Cave \& M. Lodge, Understanding Regulation: Theory, Strategy, and Practice, $2^{\circ}$ ed. (Oxford: Oxford University Press, 2012), 25-39, donde establecen cinco criterios de "buena regulación".

${ }^{14}$ Como señala Luis Cordero, Lecciones de derecho administrativo, $2^{\mathrm{a}}$ ed. (Santiago: Thomson Reuters, 2015), 416, el propósito de las acciones contenciosas administrativas en general es proveer de tutela judicial efectiva de los derechos de particulares en sus vínculos con la Administración, cuando ésta ha actuado contraviniendo el ordenamiento jurídico, llevando al juez a anular un acto, condenar a pagar una suma a la Administración por los daños que pudo ocasionar o reconocer una situación jurídica concreta, entre las más relevantes. Así, el eje sobre el cual descansa el contencioso administrativo, además de la necesaria intervención de una autoridad administrativa que se desea controlar, es el ejercicio de la jurisdicción, mediante un proceso sometido a las reglas generales de la intervención judicial, es decir: (a) derecho a una tutela judicial efectiva; (b) derecho a acceder a un tribunal; (c) prohibición de indefensión; (d) derecho a un proceso sin dilaciones indebidas; (e) derecho a una resolución judicial sobre el fondo debidamente motivada; (f) derecho a los recursos en contra de la decisión judicial; y (g) derecho a ejecutar lo juzgado.

${ }^{15}$ Por ejemplo, adoptando esta perspectiva puramente orgánica, Cane indica que esta revisión puede ser clasificada en "revisión judicial" (en sentido restringido), la que es realizada por organismos judiciales (cortes) superiores, y revisión "no-judicial", la que es efectuada por otras entidades. A su vez, algunas de estas últimas son internas a la agencia a la que pertenece quien adopta la decisión primaria (por ejemplo, un oficial o panel revisor que es parte de la agencia), mientras que en otros casos dichas entidades son externas. Véase P. Cane, "Judicial Review in the Age of Tribunals", Public Law 2009, n. 3 (2009): 479-500. En el derecho anglosajón, tales entidades se conocen con el nombre de tribunals, en contraposición a las courts regulares. En el derecho chileno, a los primeros suele denominárseles "tribunales especiales". Un estudio orgánico de estos últimos es efectuado por Ferrada, "Los tribunales" (ver nota 3 ). 
las facultades investigativas, persecutorias y decisorias entre el órgano decisor primario y el revisor, y/o en las características del procedimiento (inquisitorio o adversarial). ${ }^{16} \mathrm{La}$ naturaleza de los órganos decisor y revisor suele quedar implícita en el análisis o carece de mayor relevancia práctica. Por su parte, otros autores han optado por un enfoque más bien descriptivo, centrado en el ámbito de actuación de los órganos revisores (lo que en ocasiones se conoce como el "margen de apreciación”) en las diversas áreas sometidas a su escrutinio, y —además- en determinar cómo dicho ámbito es compatibilizado con las atribuciones conferidas al decisor primario. ${ }^{17}$

Como una forma de ilustrar nuestra tesis central, el trabajo expone las características institucionales del mecanismo de revisión en dos ámbitos crecientemente relevantes de la legislación chilena: la libre competencia y la normativa medioambiental. Para ello, describimos cómo han sido establecidas y cómo interactúan las dos variables institucionales en ellos. Si bien desde un punto de vista sustantivo (por lejos el más analizado en la literatura $)^{18}$ pudiera parecer extraño analizar es-

${ }^{16}$ Un ejemplo en el derecho chileno de libre competencia es el muy buen trabajo de J.J. Romero, Ejecución y cumplimiento de un marco normativo de libre competencia: influencias y opciones de diseño (Santiago: Thomson Reuters, 2014) 350 y ss.

${ }^{17}$ En materia de libre competencia, este enfoque es usual. Por ejemplo, H. Schweitzer, "Judicial Review in EU Competition Law", en Handbook on European Competition Law, editado por I. Lianos \& D. Geradin, vol. II: Enforcement and Procedure (Cheltenham y Northampton, UK: Edward Elgar Publishers, 2013), 491; J.C. Laguna de Paz, "Understanding the Limits of Judicial Review in European Competition Law", Journal of Antitrust Enforcement 2, n. ${ }^{\circ} 1$ (2014): 203-24. Algunas de las materias en las cuales se analiza el "margen de apreciación" son multas, control de fusiones, control de procedimiento y estándar de prueba, entre otras.

${ }^{18}$ De hecho, en la literatura comparada son pocos los análisis institucionales en ambos sectores. Como expresa un autor, en el contexto de libre competencia, "mucho más tiempo es gastado en medir las decisiones de las agencias de competencia en relación a su fidelidad a los principios establecidos por legisladores muertos hace tiempo, que en preguntarse si la decisión específica en cuestión representa una respuesta sensible frente las fuerzas institucionales y restricciones bajo las cuales las agencias de competencia operan en el día a día" ( "...far more time is spent measuring the decisions of the antitrust agencies against their fidelity to the principles of long-dead legislators, than on inquiring whether the specific decision in question represented a sensible response to the institutional forces and constraints under which the antitrust agencies actually operate on a day-to-day basis"). Ver W. Kovacic, "Institutional Design, Agency Life Cycle, and the Goals of Competition Law", Fordham Law Review 81, n. 5 (2013): 2165. 
tas dos áreas de manera conjunta, en Chile ambas presentan un diseño institucional que resulta similar a primera vista, caracterizado fundamentalmente por la existencia de agencias administrativas y tribunales especializados. En ambos sistemas, las decisiones de estos tribunales son revisadas por la Corte Suprema, por medio de diversos recursos y, por tanto, con diferentes estándares de revisión. ${ }^{19}$ Para los efectos de este trabajo, este entramado institucional justifica de manera suficiente la revisión conjunta y permite extraer conclusiones de política pública relevantes.

Antes de continuar, es importante precisar algunas cuestiones. Primero, no pretendemos argumentar que un modelo que incorpora tribunales especializados es necesariamente el más adecuado para lidiar con los casos en un área determinada. Ni siquiera utilizamos este argumento respecto de las dos áreas de la legislación chilena que utilizamos como ejemplo. La discusión sobre si este modelo es superior a otros queda fuera del ámbito autoimpuesto en este trabajo. ${ }^{20}$ Segundo, en este trabajo no nos referimos directamente a cuál debiera ser el contenido de la

${ }^{19}$ Por cierto, existen diferencias cruciales entre ambos modelos, cuyas consecuencias exploramos más adelante.

${ }^{20}$ En la literatura es posible encontrar estudios a favor y en contra de la especialización. De hecho, autorizadas opiniones abogan por el generalismo judicial. Por ejemplo, Shapiro ha prevenido que "en la medida que (las cortes) se especializan, pierden la cualidad central que los distingue claramente de la Administración" ("to the extend that [courts] specialise, they lose the one quality that clearly distinguishes them from administrative lawmakers"). Ver Martin Shapiro, The Supreme Court and Administrative Agencies (New York: Free Press, 1968), 53. En sentido similar, uno de los jueces de apelaciones en Estados Unidos ha indicado que "me gusta el hecho de que los jueces federales sean generalistas. Usualmente digo que los jueces deben ser los últimos generalistas que quedan en la vida profesional, y he resistido poderosamente cualquier sugerencia de que las cortes federales se vuelvan especializadas en un área en particular" ("I like the fact that federal judges are generalists. I often say that judges may be the last generalists left in professional life, and I have resisted mightily any suggestion that the federal courts becomes specialized in any particular area"). Ver Chief Judge Deanell R. Tacha, U.S. Court of Appeals for the Tenth Circuit, en Lawrence Baum, Specialising the Courts (Chicago: The University of Chicago Press, 2012), 2. Por su parte, J.D. Wright \& A.M. Diveley, "Do Expert Agencies Outperform Generalist Judges? Some Preliminary Evidence from the Federal Trade Commission", Journal of Antitrust Enforcement 1, n. ${ }^{\circ} 1$ (2013): 82-103, prueban empíricamente que la agencia especializada de competencia en EE.UU. no ha tenido una performance superior a los tribunales generalistas, aspecto destacado por R. Posner, Antitrust Law, $2^{\mathrm{a}}$ ed. (Chicago: The University of Chicago Press, 2001), 280. 
revisión judicial (sea procesal o sustantiva), sino a cómo dicho contenido es moldeado e influenciado por la institucionalidad. Nuestro enfoque es esencialmente uno de diseño institucional. ${ }^{21}$ En fin, y relacionado con lo anterior, tampoco adoptamos aquí una perspectiva empírica; es decir, no hacemos una revisión crítica y exhaustiva de las decisiones adoptadas por los tribunales medioambientales, de libre competencia o por la Corte Suprema, sino sólo utilizamos algunas de ellas como apoyo para nuestra argumentación.

Fuera de esta introducción, este trabajo se organiza de la siguiente forma. La parte 2 presenta el marco teórico. Analizamos de manera detallada cada una de las variables institucionales y las consecuencias que su elección puede generar, para luego relacionarlas y extraer algunas conclusiones respecto del comportamiento del regulador frente a ellas. A continuación, en la parte 3, ejemplificamos la teoría. Comenzamos por explicar de modo general la creciente demanda por un mayor expertise y especialización surgida en nuestro derecho, especialmente desde los inicios de los años 2000, ${ }^{22}$ para luego especificar la discusión aplicando la interrelación de las variables en los dos sistemas administrativos antes indicados: la libre competencia y la normativa medioambiental. En particular, enfatizamos el impacto que ha tenido la presencia de expertos en las políticas públicas sectoriales y el rol que crecientemente ha ido asumiendo la Corte Suprema chilena, el cual sólo puede ser entendido cuando se le sitúa en el más amplio contexto institucional. La parte 4 y final concluye.

\section{LAS VARIABLES INSTITUCIONALES Y SU INFLUENCIA EN LAS DECISIONES REGULATORIAS}

Al analizar el diseño institucional de un determinado régimen de revisión judicial, existen diversas cuestiones que deben ser conside-

${ }^{21}$ Entendemos, sí, que este último es eminentemente limitado cuando es considerado de forma separada de los anteriores.

22 En este sentido, concordamos con quienes postulan que para entender los cambios en materia regulatoria y el rol de la experticia en la definición de políticas públicas, es esencial examinar la forma en que se han desarrollado las instituciones. Por ejemplo, M.A. Eisner, Antitrust and the Triumph of Economics: Institutions, Expertise, and Policy Change (Chapel Hill: University of North Carolina Press, 1991). 
radas, pero - como argumentaremos - dos resultan centrales. ${ }^{23} \mathrm{La}$ primera, y más obvia, es la naturaleza del ente revisor: ¿debe éste ser especializado o debe la cuestión ser entregada a la jurisdicción general? Como hemos adelantado, la opción por uno u otro modelo - especialización o régimen general — influye en los incentivos que dichos órganos tendrán al momento de ejercer sus funciones. Esto es lo que consideramos como primera variable institucional, cuyo desarrollo histórico y contenido específico tratamos en la sección 2.1. Luego, una segunda cuestión, vinculada a la anterior, pero diferente, dice relación con el instrumento que el ordenamiento otorga al órgano revisor para decidir la materia específica sometida a su conocimiento. El instrumento determina en buena medida (aunque no de forma exclusiva) el estándar de revisión. Ésta es lo que llamamos la segunda variable institucional, que desarrollamos en la sección 2.2. Subyacente al análisis de ambas variables se encuentra la cuestión del ámbito de la decisión. El órgano decisor o el revisor adoptarán diversas posturas, diversos grados de intervención, como resultado de la interrelación entre los incentivos dados por la primera y las posibilidades entregadas por la segunda, lo que en definitiva impactará en el comportamiento del decisor primario. La sección 2.3 detalla estas cuestiones.

\subsection{Primera variable: especialización versus régimen general}

La primera variable de importancia para el diseño institucional tiene un carácter orgánico. Desde este punto de vista existen múltiples cuestiones que definir. Algunas de ellas, por ejemplo, dicen relación con la decisión primaria: si ésta será adoptada por el mismo órgano que instruye la investigación y es parte en el litigio, o por un órgano separado. Ésta es una decisión de carácter primordialmente procesal, que dice relación con las garantías otorgadas a los intervinientes, particularmente la independencia judicial y otras que se engloban bajo el concepto ge-

${ }^{23}$ Esta sección extiende los planteamientos expuestos en J. Tapia \& S. Montt, "Judicial Scrutiny and Competition Authorities: The Institutional Limits of Antitrust", en The Global Limits of Competition Law, editado por D. Sokol \& I. Lianos (Stanford: Stanford University Press, 2012), 141-157. 
nérico de procedural fairness, "justicia procesal" 24 o debido proceso. ${ }^{25}$ Otras opciones orgánico-procesales dicen relación con el procedimiento frente al decisor primario y al revisor: adversarial o inquisitorio; con la decisión de ubicar al organismo revisor dentro o fuera del poder judicial; o bien con la opción entre crear una agencia multisectorial o de objetivo único. ${ }^{26}$ Sin embargo, todas estas decisiones — sin duda importantes en sí mismas - resultan a nuestro juicio secundarias frente a la decisión de optar por un revisor especializado o generalista. Como veremos, esta última opción es la única, entre todas las decisiones orgánicas, que tiene un impacto significativo en los incentivos entregados al órgano decisor y que, por tanto, afecta el modo en que éste adopta sus decisiones en primera instancia.

\subsubsection{Los origenes de la especialización}

El concepto y desarrollo de la especialización judicial está fuertemente ligado al desarrollo paralelo de la administración moderna del Estado y constituye uno de los problemas centrales desde el establecimiento del modelo liberal de estado de derecho. ${ }^{27}$ Por lo mismo, no es posible analizar la especialización judicial sin referirse, al menos de manera somera y descriptiva, a los cambios que ha sufrido la Administración.

${ }^{24}$ La justicia procesal ha sido entendida por la doctrina como comprensiva de cuatro principios centrales: voz, neutralidad, respeto y confianza (véase, por ejemplo, T.R. Tyler, "Procedural Justice and the Courts", Court Review 44: 26). Sin embargo, existen diversas formas de referirse al contenido de estos principios. Así, la "voz" puede ser entendida como bilateralidad de la audiencia; la neutralidad puede ser asociada a la independencia del juzgador; y tanto el respeto como la confianza pueden ser consideradas manifestaciones de la legitimidad propia de un sistema judicial.

${ }^{25}$ El Tribunal Constitucional chileno ha sostenido que si bien el sistema que se diseñe es responsabilidad del legislador, éste debe cumplir con estándares básicos de debido proceso. En términos sencillos, esto significa que no se puede dictar un acto administrativo que imponga una medida de gravamen, "sin que se instruya un procedimiento administrativo que permita al afectado una adecuada defensa de sus derechos" (STC rol 1413- 09, c. 26).

${ }^{26}$ Sobre este último caso, véase A. Ottow, "Erosion or Innovation? The Institutional Design of Competition Agencies - A Dutch Case Study", The Journal of Antitrust Enforcement 2, n. ${ }^{\circ} 1$ (2014): 25-43 (explicando el paso de la agencia holandesa de competencia a agencia multifuncional).

${ }^{27}$ Véase nota 5. 
Como es sabido, el constitucionalismo moderno descansa en un delicado balance entre poder y libertad, el cual, a su vez, se sustenta en tres principios básicos: supremacía constitucional, que la Constitución es la ley fundamental de un territorio y que la judicatura es su guardián. ${ }^{28}$ En la concepción de la teoría originaria del Estado constitucional surgida a partir de los procesos revolucionarios del siglo XVIII, es el juez el encargado de mantener la estricta separación entre la creación de las normas (entregada al Parlamento) ${ }^{29}$ y su aplicación (entregada a la Administración). De aquí que la independencia de la función jurisdiccional y su sumisión a la legalidad fueran también elevadas a la categoría de pilares básicos de los sistemas jurídicos liberales. ${ }^{30}$ En estos últimos, un juez revisa las actuaciones de los órganos administrativos, realizando un mero ejercicio de subsunción, y vela porque ellas estén sometidas en todo momento al derecho. Legalidad y control son los dos principios sobre los cuales se sustenta todo el entramado constitucional. ${ }^{31}$

Sin embargo, las fronteras de la actuación estatal comenzaron a ser fundamentalmente redefinidas desde mediados del siglo XX, cuando los gobiernos contemporáneos crecieron tanto en escala como en complejidad. De un lado (el menos relevante para nuestros propósitos), el tamaño relativo del sector público se expandió de forma considerable. ${ }^{32}$

${ }^{28}$ Véase M. Loughlin, Foundations of Public Law (Oxford: Oxford University Press, 2010), 312 y ss.; L. Favoreu (coord.), Droit Constitutionnel (Paris: Dalloz, 1998); E. Zoller, Introduction to Public Law (Leiden: Martinus Nijhoff Publishers, 2010); P. Weil, Derecho administrativo (Madrid: Civitas, 1986); y E. García de Enterría, La lengua de los derechos, $3^{\mathrm{a}}$ ed. (Madrid: Civitas Civitas, 2009).

${ }^{29}$ Normalmente, el órgano "legislador" es el poder legislativo. En el derecho chileno, sin embargo, el rol pertenece en gran medida al poder ejecutivo conjuntamente con el Congreso, reconociéndosele la calidad de "colegislador". No obstante, en lo sucesivo mantendremos la nomenclatura tradicional.

30 Para una explicación general, véase I. de Otto, Derecho constitucional: Sistema de fuentes, $2^{\mathrm{a}}$ ed (Barcelona: Ariel Derecho, 1988), 284 y ss.; Zoller, Introduction.

31 Véase, en este sentido, L. Cordero Vega, El control público (Santiago: Legal Publishing, 2010); E. Carolan, The New Separation of Powers. A Theory for the Modern State (Oxford: Oxford University Press, 2009); F. Rubio Llorente, Las formas del poder. Estudios sobre la Constitución (Madrid: Centro de Estudios Constitucionales, 1997).

${ }^{32}$ Véase S. Peltzman, "The Growth of Government", Journal of Law and Economics 23: 209 (1980), quien presenta evidencia de este punto en algunas naciones. 
De otro, desde aquel entonces los problemas públicos derivados de las actividades económicas tendieron a complejizarse, presentando desafíos antes no previstos en términos de las políticas públicas necesarias para materializar los fines perseguidos. ${ }^{33}$ La manifestación más fuerte de la redefinición llegaría a partir de la década de los 80 , cuando la complejización no sólo se plasmó en los procesos "hermanos" de privatización, des- y re-regulación, liberalización (es decir, promoción de competencia en servicios tradicionalmente considerados monopólicos) y desintegración de estructuras verticales, sino también en la mayor relevancia que comenzaron a adquirir los objetivos sociales, en la disminución de la frontera público-privada, etcétera. ${ }^{34} \mathrm{El}$ avance de lo que sería luego denominado el "Estado regulador" 35 o, más genéricamente, del "capitalismo regulatorio" ${ }^{36}$, comenzó a presentar serios desafíos tanto para la creación del derecho como para su aplicación.

${ }^{33}$ Como indicara Forsthoff, "la técnica viene por todas partes al encuentro de la Administración" (E. Forsthoff, Sociedad industrial y administración pública (Madrid: Escuela Nacional de Administración Pública, 1967), 102). Para un análisis detenido de esta evolución en el derecho administrativo, véase R. Pantoja, Derecho administrativo. Clasicismo y modernidad (Santiago: Editorial Jurídica de Chile, 1994); J. Barnes, "Transformaciones (científicas) del derecho administrativo", Revista Argentina del Régimen de la Administración Pública 430: 209; y L. Parejo Alfonso, Transformación y ¿reforma? del derecho administrativo en España (Madrid: INAP - Global Law Press, 2012).

${ }^{34}$ Para una presentación de esta idea comparando experiencia de Francia, Reino Unido y Estados Unidos, véase T. Prosser, The Regulatory Enterprise: Government, Regulation, and Legitimacy (Oxford: Oxford University Press, 2010).

35 Sobre este concepto, véase, por ejemplo, G. Majone, "The Rise of the Regulatory State in Europe", West European Politics 17 (1994): 77; y C. Scott, "Regulation in the Age of Governance. The Rise of the Post-Regulatory State", en The Politics of Regulation: Institutions and Regulatory Reform for the Age of Governance, editado por J. Jordana \& D. Levi-Faur (Cheltenham, UK: Edward Elgar Publishing, 2004), 145.

36 J. Braithwaite, Regulatory Capitalism: How It Works, Ideas for Making It Work Better (Cheltenham, UK: Edward Elgar Publishing, 2008); D. Levy-Faur, "The Global Diffusion of Regulatory Capitalism", Annals of the American Academy of Political \& Social Sciences 598 (2005): 12; J. Jordana, "Globalizing Regulatory Capitalism”, Annals of the American Academy of Political \& Social Sciences 598 (2005): 184. El concepto de "capitalismo regulatorio" sintetiza de forma muy precisa que los mercados son simplemente un mecanismo regulatorio en el que confluye un gran número de formas de regulación estatales y no-estatales. La regulación es hoy difusa y fragmentada, y engloba un amplio ser de actividades de control y de policía que van más allá de la dirección del Estado, pero reservándole a éste un rol dominante. 
Lo anterior trajo como consecuencia cambios importantes en la estructura del derecho, manifestados centralmente en el desarrollo de áreas "menos tradicionales", esto es, distintas del derecho constitucional, civil, procesal y penal. ${ }^{37}$ Los avances prácticos en materias corporativa, financiera, regulatoria, de competencia, propiedad intelectual, farmacéutica o incluso medioambiente - todas las cuales usualmente se vinculan a cambios tecnológicos, complejas operaciones financieras ( $f$ nancial engineering) o productos nuevos-, no sólo permitieron lidiar de mejor manera con la nueva realidad económica y social, sino que demandaron una adaptación en paralelo de las normas bajo las cuales aquellos avances se desarrollaban. Esto significó cambios profundos en los derechos de inspiración civil continental. Por ejemplo, en varias de estas nuevas áreas (o al menos en parte de ellas) tiende a primar la técnica de regular por estándares en desmedro de las reglas, ${ }^{38}$ lo que redunda en la creación de estatutos legales generales, dotados de poco contenido específico en sí mismos y sujetos a un alto nivel de interpretación. Tanto ésta como otras diferencias basales en la estructura del derecho fueron las que, en buena medida, comenzaron a demandar arreglos institucionales especiales que facilitaran su aplicación.

En efecto, la tarea consecuencial consistió en determinar cuál era el ente más capacitado para lidiar con las nuevas e intrincadas funciones estatales. Tanto la rapidez del comercio y la complejidad de los problemas, como las limitaciones propias del proceso de formación de la ley, evidentemente impedían acudir a la legalidad estricta como solución. Frente a la nueva realidad jurídica, entonces, la Administración se alzó como la entidad mejor posicionada para dotarla de contenido y efectuar su aplicación. ${ }^{39}$ La explicación más extendida acerca de este

${ }^{37}$ Aunque algunas de éstas, por cierto, también se han vuelto más complejas (especialmente el derecho penal).

38 Para un análisis económico de esta distinción, véase L. Kaplow, "Rules Versus Standards: An Economic Analysis”, Duke Law Journal 42 (1992): 557-629.

${ }^{39}$ Véase C. Sunstein, After the Rights Revolution: Reconceiving the Regulatory State (Cambridge, MA - London: Harvard University Press, 1990), 111: "Por cierto, las reformas legislativas deben vencer una enorme carga de inercia. Es a través de la interpretación, en las cortes y el poder ejecutivo, que las mejoras regulatorias, [ya] intercaladas por cierto, pueden ser realizadas más fácilmente" ("Indeed, legislative reform must overcome an enormous burden of inertia. It is through interpretation, in the courts and the executive branch, that regulatory improvements, interstitial to be sure, can be brought about most easily"). 
fenómeno en la literatura es que la complejización de los problemas públicos trajo como consecuencia la necesidad de que el legislador "encargara" o "delegara" (dependiendo del contexto institucional general de cada jurisdicción específica) una serie de tareas y responsabilidades en organismos administrativos, los que vieron ampliado de manera importante su espacio de actuación. ${ }^{40}$ Esto relativizó, de algún modo, el concepto de legitimidad plena de la ley como mecanismo para la resolución de problemas públicos. ${ }^{41}$ La encomienda o delegación podía ser explícita o producirse de manera implícita, esto es, cuando la redacción normativa posee cierto grado ambigüedad, por ejemplo, producto del carácter esencialmente flexible de los objetivos perseguidos por la legislación; o bien cuando presenta vacíos que deben ser llenados por la vía interpretativa. ${ }^{42}$ Cualquiera sea el caso, el diseño normativo y de po-

${ }^{40}$ Para una exposición de las críticas centrales al modelo de delegación, véase C. Radaelli \& F. de Francesco, "Regulatory Impact Assessment", en The Oxford Handbook of Regulation, editado por R. Baldwin, M. Cave \& M. Lodgem (Oxford: Oxford University Press, 2010), 279 y ss.

${ }^{41}$ Como ha dicho C. Cabo Martín - Sobre el concepto de ley (Madrid: Ed. Trotta, 2000), 95-, en la medida en que la "lógica intervencionista se impone y la legislación pierde su carácter general y pasa a incorporar, de un lado, y a afectar, de otro, a intereses concretos, se entiende que ahora el espacio de la decisión ya no corresponde a la representación general sino que debe ser compartida con los intereses concretos implicados, a los que, desde la óptica garantista individual, es necesario integrar en el procedimiento. Así, el procedimiento parlamentario actual incluye efectivamente intereses particulares extraparlamentarios que intervienen, bien en el momento de la iniciativa, bien en el de las fases posteriores y de las más distintas formas, y que desvirtúan aquellos dos objetivos generales a los que servía el procedimiento parlamentario como instrumento democrático e imparcial en la elaboración de la ley. Por esta vía vuelve a aparecer el impacto administrativista, no sólo por su contenido, sino porque el procedimiento parlamentario se convierte a la lógica del procedimiento administrativo en cuanto toda esa inclusión de los intereses afectados adquiere el sentido que en este último se asigna a la 'audiencia del interesado'. Hay que tener en cuenta que con ello, además, se legitiman nuevos sujetos capaces de aumentar la complejidad de las demandas tanto desde fuera como dentro del procedimiento, dadas las posibilidades que ofrece la deducción de inconstitucionalidad por vicios procedimentales".

42 Nótese que el carácter implícito de la delegación bien puede provenir de una decisión expresa del legislador (lo que Kovacic, "Institutional Design", 2166, denomina "ambigüedad estratégica"). Por ejemplo, éste puede saber de antemano que leyes con propósitos múltiples conllevan un mayor riesgo de que ciertas disposiciones se confronten unas con otras. Sin embargo, esa multiplicidad de objetivos bien puede ayudar a obtener los quórums necesarios para aprobar la ley. 
lítica pública (policy-making) pasó a estar radicado fundamentalmente en el poder ejecutivo en desmedro del legislativo. ${ }^{43}$

Este fenómeno se agudizaría en la era post privatización, con la creación y masificación, en diversas jurisdicciones (con particular notoriedad en el derecho europeo continental), de una respuesta estatal basada en el trabajo de una serie de órganos que operan a una distancia considerable de las instituciones democráticas tradicionales, cuyos orígenes se remontan al derecho norteamericano. ${ }^{44}$ La literatura las denomina "instituciones no-mayoritarias", aunque el nombre de "agencias regulatorias independientes" es el más común. ${ }^{45} \mathrm{Su}$ fundamento radica en que el aumento en el nivel de especialización y expertise, así como su independencia de otros poderes del Estado, ${ }^{46}$ puede traer beneficios significativos no sólo en la medida que expande las capacidades administrativas, sino en cuanto permite, además, reemplazar "clientelismo" y dependencia de otras instituciones (aumentando la autonomía en la definición de políticas públicas) y enfatizar objetivos de largo plazo. ${ }^{47}$

${ }^{43}$ Véase E. Schmidt-Assmann, La teoría general del derecho administrativo como sistema (Madrid: INAP - Marcial Pons, 2003), 51-124.

${ }^{44}$ En Estados Unidos, el denominado "movimiento tecnocrático" que antecedió al llamado New Deal (entre 1933 y 1936, bajo el gobierno de F.D. Roosevelt) emanó del deseo de separar la política de la administración del Estado. A partir de este objetivo, los principios progresistas de buena administración guiaron en buena medida el diseño de las agencias durante el New Deal y la subsecuente definición de las políticas durante el período. Para un análisis detallado, véase W. Atkin, Technocracy and the American Dream: The Technocratic Movement, 1900-1941 (Berkeley: University of California Press, 1977); y M.A. Eisner, Regulatory Politics in Transition (Baltimore: John Hopkins University Press, 2000), especialmente el capítulo 2.

${ }^{45}$ Por todos, véase M. Thatcher \& A. Stone Sweet, "Theory and Practice of Non-Majoritarian Institutions", West European Politics 25 (2002): 1-22. Para el caso de Chile, L. Cordero Vega \& J.F. García, "Elementos para la discusión de las agencias independientes en Chile. El caso de las superintendencias", en Anuario de Derecho Público 2012, UDP: 415 y ss.

${ }^{46}$ De hecho, algunos autores han indicado que estas agencias serían un verdadero "cuarto poder del Estado", constituyendo ellas una manifestación de una nueva fase en el desarrollo estatal (por todos, ver nota 28: Loughlin, Foundations, 450).

${ }^{47}$ Nótese que, sin embargo, dado su carácter de "independencia", la autoridad de estos órganos proviene de fuentes distintas a la delegación del poder por parte de la legislatura. En el Estado regulador, entonces, la hipótesis de la delegación puede ser seriamente cuestionada y, por consiguiente, también pueden serlo los mecanismos de control creados bajo su influjo. Explorar estas cuestiones excede los límites autoimpuestos en este trabajo. 
Subyacente tanto a la noción de encomienda como de delegación está la creencia o convicción de que la Administración posee mayores capacidades informacionales respecto de una determinada materia que el legislador. ${ }^{48}$ Esta capacidad superior no tiene una fuente única. En este sentido, la especialización (considerada en este caso desde la perspectiva puramente subjetiva) puede ser concebida como un concepto que enmarca al menos dos elementos — similares, pero no idénticosrelacionados con el nivel de información del órgano especializado. El primero es la "experticia": un elevado nivel de conocimiento en un área sustantiva específica, en razón de su estudio pormenorizado; el segundo es la experiencia, esto es, la acumulación de un conocimiento o destreza. Un órgano será también especializado cuando deba lidiar con un alto número de decisiones en la misma materia, sobre todo si éstas se refieren generalmente a una misma área particular. De aquí que organismos con competencias altamente delimitadas vean fortalecidas sus capacidades para lidiar con ciertos temas específicos. La presencia de este elemento implica que, de manera contraria a la creencia extendida, la sola experticia no es el elemento que necesariamente define a la especialización. ${ }^{49}$

${ }^{48}$ En este sentido, por ejemplo, J. Huber \& C. Shipan, Deliberate Discretion? The Institutional Foundations of Bureaucratic Autonomy (Cambridge y Nueva York: Cambridge University Press, 2002), 215 (indicando que subyace a su modelo el que el expertise de los burócratas es superior al de los políticos); y J.L. Mahaw, Bureaucratic Justice. Managing Social Security and Disability Claims (New Haven, CT: Yale University Press, 1985), indicando que "el profesional es maestro de un arcano cuerpo de conocimiento y funda su juicio apelando a la experticia" ("the professional is master of an arcane body of knowledge and supports his judgment by appeals to expertise"). Con todo, nótese que la especialización es sólo una de las razones que explican la necesidad de delegar. Otras explicaciones enfatizan los costos de redactar legislación, mientras que una tercera "rama" (más vinculada a la creación de agencias independientes) la explica en términos de una mayor protección contra influencia política. Explorar estas hipótesis excede los límites de este trabajo. Asimismo, cuando una agencia es independiente, existe otra razón que - junto a la especialización- justifica un mayor o menor grado de delegación: que el creador de la norma anticipe que la agencia se alineará con sus propias preferencias acerca de los resultados esperados. Esto a veces se denomina ally principle o principio del aliado. Véase M. Stephenson, "Statutory Interpretation by Agencies", en Research Handbook on Public Choice and Public Law, editado por D.A. Farber \& A.J. O'Connell (Cheltenham, UK: Edward Elgar Publishing, 2010), 288.

49 De hecho, los jueces generalistas también son "expertos" en la aplicación de la ley. De acuerdo a Cane, Administrative Tribunals, 93, la distinción se debe a que los jueces no-legos "hablan sin acento", dado que los procesos son llevados en lenguaje legal. 
El nivel de la encomienda o delegación está determinado fundamentalmente por la profundidad de la especialización del ente administrativo de que se trate. Independiente de si la delegación es explícita o se produce de manera implícita, la cuestión central radica en determinar el "espacio o margen de discreción" con que será dotada la agencia. ${ }^{50}$ Dentro de dicho espacio, a ésta le es permitido seleccionar cualquier objetivo de política pública; pero le está vedado apartarse de él. ${ }^{51}$ Como habitualmente se indica, este espacio puede ser pensado como una "zona de ambigüedad" en la cual existe un rango de interpretaciones plausibles de ser elegidas teniendo en cuenta los legítimos principios interpretativos y

${ }^{50}$ Como expresa P. Menéndez ("Discrecionalidad”, en Diccionario de derecho administrativo, dirigido por S. Muñoz Machado (Madrid: Iustel, 2005), 969), la potestad discrecional se dará en los casos en que el legislador le confiere a la Administración un espacio de autodeterminación, un margen o libertad de decisión para elegir entre varias alternativas o soluciones posibles. La adopción de los actos que se dicten en ejercicio de una potestad de esa naturaleza se basará, entonces, en criterios no predeterminados por la norma que concede el margen de decisión, criterios que quedan a la libre consideración de la Administración. Con todo, la discreción es un concepto complejo, lo que se demuestra no sólo por la abundante literatura que se ha abocado a su entendimiento (por todos, véase K. Hawkings, ed., The Uses of Discretion (Oxford: Oxford University Press, 1995)), sino también por su uso diverso en las distintas jurisdicciones. Por ejemplo, el derecho administrativo francés distingue entre pouvoir discrétionnaire, que en general se refiere a la libertad de elección entre diferentes cursos de acción, y competence liée ("facultades atadas"), que aparece toda vez que el decisor, luego de calificar los hechos, debe seguir cierto curso de acción establecido por el legislador (J-C. Venezia, Le pouvoir discrétionnaire (París: Librerie Générale de Droit et Jurisprudence, 1959). En el derecho alemán, por su parte, se distingue entre Ermessen, que se refiere a la elección de "acciones-posibilidades", y Beurteilungsspielsraum, que se refiere al especial margen de apreciación del que goza un órgano administrativo cuando interpreta normas de textura abierta (J. Terchechte, "Administrative Discretion and Judicial Review in Germany", en National Courts and the Standard of Review in Competition Law and Economic Regulation, editado por O. Essens, A. Gerbrandy \& S. Lavrijssen (Groninga, PB: Europa Law Publishing, 2009), 85-86). Para los efectos de este trabajo, suficiente es considerar la discreción desde la perspectiva amplia mencionada por Menéndez de "espacio de autodeterminación" (o "esfera de autonomía", en palabras de D.J. Galligan, Discretionary Powers: A Legal Study of Official Discretion (Oxford: Clarendon Press, 1990)).

${ }^{51} \mathrm{Al}$ apartarse de dicho fin se puede configurar un vicio en la dictación del acto de la autoridad administrativa, denominado "desviación de fin o de poder". Al respecto véase C. Chinchilla, La desviación de poder (Madrid: Civitas, 1999); y C. Lledó \& J. Pardo, El vicio de la desviación de poder en los actos administrativos (Santiago: Legalpublishing - Thomson Reuters, 2013). 
el lenguaje de la norma. ${ }^{52}$ Aquí es donde juega un rol fundamental la especialización: el "tamaño" del espacio de discreción depende fundamentalmente del nivel de especialización de la agencia administrativa: aquél será mayor mientras más alto sea este nivel. Esto se explica en que, enfrentado a un cierto grado de incertidumbre acerca del real estado del arte del objeto normativo o de la verdadera conexión entre las opciones interpretativas y su resultado, el creador de la norma preferirá delegar más (en otras palabras, ampliar el espacio de discreción) en quien posee mejor información. En caso contrario, el creador de la norma simplemente tiene incentivos a redactar ésta en términos más completos.

Lo anterior explica el problema de "agente-principal" que subyace a la idea de delegación. Mientras mayores sean las capacidades informacionales de una agencia, mayores serán las asimetrías de información existentes entre la legislatura y la Administración. ${ }^{53}$ Por esto, las agencias con mandatos más específicos suelen operar con un mayor grado de autonomía respecto del poder central (éste suele ser el caso, por ejemplo, de las agencias independientes, antes mencionadas) y suelen tener mayores espacios de discrecionalidad para determinar políticas públicas. De esto deriva la importancia de establecer mecanismos para mitigar tal riesgo, tales como el uso del proceso, de incentivos u otros. ${ }^{54}$

Sin embargo, un aspecto crucial a tener en cuenta en nuestro análisis es que el proceso de encomienda o delegación a la Administración no sólo incluyó la definición de la política pública (policy-making, el área "natural" de delegación), sino que también comprendió la entrega de importantes facultades interpretativas. La explicación para esto nue-

${ }^{52}$ M. Stephenson \& A. Vermeule, "Chevron Has Only One Step", Virginia Law Review 95 (2009): 597-609. En sentido similar, G. Fernández Farreres, Sistema de derecho administrativo I, $2^{\mathrm{a}}$ ed. (Cizur Menor, Navarra: Civitas - Thomson Reuters, 2014), 456.

${ }^{53}$ Nótese que la idea de la delegación adopta la perspectiva de la clásica teoría de la elección racional (rational choice), de acuerdo a la cual el proceso regulatorio es caracterizado por oferta y demanda, $y$, tal como los mercados de bienes y servicios (y quizás en mayor medida que éstos), está plagado de "fallas", siendo las más fundamentales aquellas asociadas a las asimetrías de información (básicamente riesgo moral, selección adversa y señalización). Una pregunta relevante, que no exploramos en este trabajo, es en qué medida el aumento del pluralismo en la política llevará a una mayor necesidad de formar coaliciones y, por ende, delegar aún más en la Administración en cuestiones técnicas.

${ }^{54} \mathrm{El}$ análisis de estas cuestiones excede los límites de este trabajo. 
vamente puede atender al elemento informacional: dado que un cierto nivel de interpretación es inevitable, el legislador prefiere dotar de tal facultad de manera completa y directa, con el fin de alinear lo más cerca posible los objetivos de política pública (los cuales, como hemos indicado, son definidos por la Administración) con el resultado de la interpretación. Así, las facultades para interpretar normativa tendrían un rol coadyuvante que facilitaría el desarrollo de las políticas públicas. Por tanto, es esperable que mientras más grande sea la ventaja informacional de una agencia, más autoridad interpretativa tendrá. ${ }^{55}$

En suma, el crecimiento del rol de la Administración, tanto en materia de políticas públicas como en la tarea interpretativa, explica en buena medida los cambios consecuenciales que ha sufrido la judicatura, especialmente en lo que se refiere a la variable orgánica de la especialización, como analizamos a continuación.

\subsubsection{La especialización judicial ${ }^{56}$}

El progresivo aumento de la delegación o encomienda en la Administración, producto de las mayores demandas de especialización técnica que implicaron los cambios estatales, también trajo consecuencias profundas en la forma de lidiar con el tradicional problema de balancear poder y libertad. Si bien los jueces mantuvieron su rol de garantes del sistema, su importancia relativa en la resolución de conflictos públicos decreció de manera natural. Si, como hemos visto, la regla general es que el legislador delegará en —o encomendará a- quien tenga una ventaja informacional, prima facie, la hipótesis de la especialización favorece la alternativa de delegar en la Administración en desmedro de la judicatura, ${ }^{57}$ la cual, en particular, dejó de ser el "intérprete natural"

${ }^{55}$ En este sentido, J. Mashaw, “Agency Statutory Interpretation”, Public Law $\&$ Legal Theory. Research Papers Series 33, Yale Law School, 2003. Para una crítica jurídica a los efectos de la interpretación administrativa, véase A. Guzmán Brito, La interpretación administrativa en el derecho chileno (Santiago: Legalpublishing - Thomson Reuters, 2014).

${ }^{56}$ Véase nota 8 y el texto central al que acompaña, donde expresamos nuestra definición de especialización.

${ }^{57}$ Ésta es la clásica crítica de L.L. Fuller en el derecho norteamericano ("The Form and Limits of Adjudication", Harvard Law Review 92 (1978): 353), quien estimaba que las cortes generalistas no eran capaces de lidiar con las "cuestiones policéntricas" que afectaban intereses dispersos, propios de la regulación. 
de la legislación. Por esto, a partir de mediados del siglo XX, la Administración se transformó en la encargada primordial de determinar el adecuado balance entre derechos privados y necesidades regulatorias colectivas que subyace a todo conflicto público. Esto implicó, además, que los conflictos comenzaran a ser resueltos atendiendo a la naturaleza del problema determinado y sus fines, centrándose las decisiones en la búsqueda de un objetivo último unificador del sistema más que en un análisis casuístico basado en la protección de derechos de carácter individual. $^{58}$

Esta preeminencia administrativa, tanto orgánica como sustancial, no sólo conllevó un "choque" frontal con las competencias judiciales y la manera en que los tribunales tradicionales entendían su propio rol y aplicaban el derecho. También trajo consecuencias importantes para la estabilidad institucional, pues la señalada preeminencia contrariaba, en cierta medida, los objetivos políticos de corto plazo de la legislatura. En efecto, si el legislador calcula que sus réditos políticos en el corto plazo serán más beneficiosos si provee decisiones estables para el largo plazo, es la judicatura - no la Administración - la que se alza como el delegatario que mejor puede alcanzarlas, pues teóricamente se encuentra más alejada de la eventual influencia política. ${ }^{59}$ Es también posible afirmar que el creador de la norma simplemente prefiere no aceptar su responsabilidad por ella (blame shifting) y, por tanto, delega en el intérprete, particularmente en la judicatura, que será en definitiva quien cargue con la responsabilidad de una determinada interpretación. ${ }^{60}$ Cualquiera sea el caso, la respuesta institucional paralela natural al fortalecimiento de la Administración fue fortalecer la judicatura.

El logro de lo anterior dependía de la posibilidad de equiparar, en la mayor medida posible, a la Administración en términos de rapidez

${ }^{58}$ Más adelante volveremos sobre esta idea. Véase la nota 77 y el texto central al que acompaña.

${ }^{59}$ Esta situación está vinculada a la hipótesis de "compromisos creíbles" —credible commitment - identificada por la literatura para lidiar con el problema de la consistencia en el tiempo (time-consistency problem). Véase, por ejemplo, T.M. Moe, "Politics and the Theory of Organization", Journal of Law, Economics and Organization 7 (special): 106-29.

${ }^{60}$ Como expresa un autor, hay temas en los que los legisladores están muy dispuestos a aparecer como que han "hecho algo", pero no están igualmente dispuestos a hacer algo en particular (J.Q. Wilson, The Politics of Regulation (New York: Basic Books, 1980)). 
y experticia. En efecto, toda la idea de delegación o encomienda en la Administración y el control por la judicatura descansa en una judicatura tradicional, de carácter generalista, sea ésta del fuero común o una justicia contenciosa administrativa. ${ }^{61}$ La especialización judicial de contenido técnico, en cambio, permite a ésta al menos emular las capacidades administrativas y ejercer un mayor espacio de discreción. Por esto, no es necesario que el juez sea más experto que el decisor primario, sino que es suficiente que posea un conocimiento importante en el área (como hemos mencionado, sea que haya adquirido éste por expertise o por experiencia), de modo que pueda decidir a cabalidad incluso acerca de los detalles técnicos del problema. ${ }^{62} \mathrm{Si}$ su conocimiento (o incluso el del equipo que lo apoya) es elevado, él puede sostener que posee una competencia al menos similar a la de la agencia para lidiar con la materia en cuestión. ${ }^{63}$ Por cierto, es indudable que, por una cuestión de recursos, capacidades humanas disponibles y objetivos, la judicatura nunca equiparará completamente a la Administración. La pregunta de por qué ampliar las capacidades judiciales dice relación, esencialmente, con una cuestión de grado; con cuál será el acento que se dará a la protección de derechos individuales versus fines públicos o, más ampliamente, al balance entre libertad y poder.

En otras palabras, la especialización judicial técnica refleja una doble desconfianza: en el actuar de la Administración y su capacidad de dar un uso adecuado a los espacios de discrecionalidad (el problema revolucionario del siglo XVIII), frente a lo cual la judicatura proveería la independencia necesaria que actúa como contrapeso; y también en las capacidades técnicas de los jueces tradicionales, generalistas, para controlar las capacidades supuestamente "exorbitantes" que dicha Administración habría adquirido producto de la complejización de las relaciones económicas (el problema "revolucionario" del siglo XX), frente a lo cual la judicatura especializada proveería un resguardo técnico adecuado para lidiar con los

${ }^{61}$ Véase, sin embargo, la advertencia señalada en nota 20.

${ }^{62}$ Algunos han planteado el supuesto erróneo de que la experticia del revisor debe ser mayor: R.M. Levin, "Identifying Questions of Law in Administrative Law", Georgetown Law Journal 74 (1985): 1 y ss.

${ }^{63}$ Por tanto, la delegación podría incluso recaer directamente en esta última y no en la Administración, como efectivamente acontece en ciertos sistemas normativos. 
problemas derivados de ella. ${ }^{64}$ Siendo así, las raíces de la especialización judicial técnica son - podría sostenerse- eminentemente políticas.

La visión recién descrita se condice con las diversas razones que suelen darse en el debate público para justificar la opción por una judicatura especializada. Entre otras, están incrementar la uniformidad y la predictibilidad, introduciendo coherencia lógica a los objetivos de una parte del sistema legal, o favorecer "mejores decisiones" (independiente del contenido que se pretende atribuir a esta expresión). Como se observa, nuevamente una explicación de tipo informacional subyace al hecho de que el legislador considera que los motivos aludidos, $u$ otros, son valorables y suficientes desde la perspectiva de la política pública: una mayor especialización permitiría protegerlos de una forma más adecuada, efectiva o eficaz. Por el contrario, supuestamente los jueces generalistas no estarían en posición de velar de la misma forma por los objetivos valorados por el legislador, ya sea, por ejemplo, debido a la escasez de jurisprudencia verdaderamente relevante (o su relativa incoherencia o baja densidad normativa) antes de la introducción de especialización, o por otras razones o creencias quizás más subjetivas.

La conveniencia de introducir especialización técnica debe, sin embargo, considerar también los posibles costos. Al menos uno de ellos es la pérdida de consistencia ideológica entre áreas y agencias diversas. Es dable pensar que, dentro de determinados rangos, las agencias exhibirán una cierta línea ideológica (sea conservadora o liberal, en términos generales) afín al gobierno de turno, lo que aumentará mientras más centralizado sea el control o la influencia que el Presidente pueda ejercer sobre cada agencia determinada (es decir, mientras menos independiente sea). Este incentivo puede perderse si una agencia específica se alinea, de alguna forma, con la judicatura; y, como veremos, tienen incentivos para esto. ${ }^{65}$

\subsubsection{Los incentivos derivados de la especialización técnica de la justicia}

Al menos desde un punto de vista teórico, la revisión puede ser desplegada en un continuo de opciones que va desde el escrutinio mínimo de la decisión de la instancia previa (de sus supuestos estrictamente

${ }^{64}$ Como veremos, éste fue precisamente el caso en el derecho chileno (ver sección 3.1.1).

${ }^{65}$ Ver sección 2.3.1. 
reglados) hasta la total sustitución de la decisión adoptada en esa instancia. Estos dos extremos representan dos doctrinas administrativas acerca de los límites que el control judicial impone a las decisiones regulatorias: la "deferencia" y la "no-deferencia". ${ }^{66}$ Ambos enfoques son meramente referenciales, pero no obstante resultan muy útiles cuando son considerados como "atajos" para referirse a una mayor discreción administrativa o una mayor discreción judicial, respectivamente. Por esto, sin perjuicio de que el control judicial es una cuestión de grado, la dicotomía es útil como herramienta analítica y, en este sentido (sólo en este sentido), el estudio del escrutinio de las decisiones puede ser realizado aplicando este lenguaje.

La deferencia indica que toda vez que el significado de una norma es ambiguo con respecto a la específica cuestión de derecho que se trata de resolver, o cuando el legislador ha entregado explícitamente una autorización a la Administración ya sea para decidir el contenido de una política pública o completar la regulación por vía administrativa, la judicatura debiera rehusar considerar el mérito legal de la interpretación utilizada en la decisión de la instancia previa. Esto es, la deferencia otorga al regulador un amplio espacio de discreción en sus pronunciamientos ${ }^{67}$ sin que esto implique, por cierto, inmunidad jurisdiccional. ${ }^{68}$ Por su parte, la no-deferencia puede ser simplemente definida de un modo negativo, esto es, como ausencia de deferencia. Así, el revisor examina (o re-examina) y decide respecto de parte o todos los aspectos sustanciales y procedimentales ya resueltos en la instancia previa. En su versión más extrema (que aquí denominaremos "interferencia"), la no-deferencia implica la completa sustitución de la decisión de la instancia previa por aquella que el revisor considera es la correcta

${ }^{66}$ La referencia a los "grados de deferencia" es común en la literatura anglosajona. Entre otros, véase P. Craig, Administrative Law, 6 ed. (London: Sweet \& Maxwell, 2008), 615; A.L. Young, "In Defence of Due Deference", Modern Law Review 72 (2009): 554; y P. Daly, "Deference on Questions of Law", Modern Law Review 74 (2001): 694, todos en el derecho inglés. En el derecho norteamericano, véase E.H. Tiller, "Controlling Policy by Controlling Process: Judicial Influence on Regulatory Decision Making", Journal of Law, Economics \& Organization 14, n. 1 (Spring 1998): 114-117; S. Breyer, "Judicial Review of Questions of Law and Policy", Administrative Law Review 38 (1986); y Levin, "Identifying Questions": 43 (ver nota 62).

${ }^{67}$ Sobre este concepto, ver nota 50.

${ }^{68}$ Cordero Vega, Lecciones de derecho, 431 (ver nota 14). 
interpretación de la cuestión a ser decidida, pudiendo incluso llegar a reemplazar el acto emanado de la agencia. Por tanto, mientras más cercana esté la no-deferencia a la interferencia, más reducido es el nivel de aceptación de la decisión realizada en la instancia previa.

Como hemos adelantado, el nivel de especialización técnica afecta crucialmente el ámbito de la revisión y la extensión de la discrecionalidad administrativa o judicial. De acuerdo a lo señalado, la discreción se refiere normalmente a cuestiones de hecho, de derecho o de política. ${ }^{69}$ Debido a su carencia de conocimiento experto o su falta de experiencia en las materias a ser decididas, es esperable que un revisor generalista no examine todos los aspectos de la decisión previa, sino que su examen se circunscribirá a los aspectos procesales y a verificar que no existan vulneraciones flagrantes del derecho, lo que implica un control de los aspectos estrictamente reglados y de la suficiencia de la motivación para evitar la arbitrariedad..$^{70}$ Por el contrario, las cuestiones de hecho y de política

${ }^{69}$ Entre otros, véase R. Dworkin, Taking Rights Seriously (Cambridge, Mass: Harvard University Press, 1977), 22; H.W.R. Wade \& C.F. Forsyth, Administrative Law, $9^{a}$ ed. (Oxford: Oxford University Press, 2004), 250 y ss.; S.G. Breyer, R.B. Stewart, C.R. Sunstein \& M.L. Spitzer, Administrative Law and Regulatory Policy: Problems, Text, and Cases, $5^{\mathrm{a}}$ ed. (New York: Aspen, 2002), 227. Por cierto, las categorizaciones pueden ser difusas en la práctica. Aunque la distinción suele ser usada en la práctica jurisprudencial comparada, muchos autores indican que ella no resulta útil como guía dada su posibilidad de ser manipulada en la práctica: los jueces interpretarán una cuestión como de hecho o de derecho según sea su deseo de ejercer control o por razones de conveniencia procesal (véase, por ejemplo, W.A. Wilson, "Questions of Degree", Modern Law Review 32 (1969): 361-376; de modo similar, rechazando las categorías "puras", véase C.F. Edley Jr., Administrative Law: Rethinking Judicial Control of Bureaucracy (New Haven, CT: Yale University Press, 1990). En el derecho norteamericano, éste fue un argumento recurrente de algunos adherentes al realismo legal. Por otra parte, existen muchas cuestiones "mixtas" de difícil clasificación (Levin, "Identifying Questions"). Sin embargo, al igual que otras, la distinción no deja de ser útil como herramienta analítica para nuestros propósitos.

${ }^{70} \mathrm{El}$ derecho inglés provee un buen ejemplo de esta revisión limitada. En dicha jurisdicción todas las cuestiones de derecho son revisables por las cortes desde la decisión de la House of Lords en el caso Page ( $R$ v Hull University Visitor ex parte Page [1993] AC 682). Al mismo tiempo, las cortes inglesas tradicionalmente han declinado adoptar decisiones en cuestiones de hecho y política (véase, por ejemplo, C. Harlow y R. Rawlings, Law and Administration, (Cambridge y New York: Cambridge University Press, 2009), 311). Confirmando este punto, véase: $R v$ DG Telecommunications ex parte Cellcom, [1999] COD 105, at para. 26 (per Lightman J): "[L]a corte no debiera apurarse en impugnar las decisiones sobre hechos realizadas por un decisor experto y con experiencia, [y] debe ser por cierto más 
serán normalmente dejadas a la discrecionalidad del decisor previo. En lenguaje estadístico, el revisor se mantendrá en el ámbito de las opciones discretas, lo que tendrá como resultado esperado una mayor deferencia. ${ }^{71}$

Tales argumentos resultan débiles en presencia de revisores especializados de carácter técnico. La especialización crea incentivos a incrementar la discreción mediante la revisión de todos los aspectos de la decisión previa. Haciendo uso nuevamente del lenguaje estadístico, el revisor especializado posee opciones continuas. Un mayor grado de especialización técnica permite al revisor sentir más confianza en sus propias capacidades cuando lidia con materias que en principio parecen requerir de un conocimiento especial y, por tanto, se siente capacitado para juzgar temas complejos (incluso técnicamente). Como algunos autores han sostenido, el conocimiento especializado provee un mejor entendimiento de los objetivos de políticas relevantes, reduce la probabilidad de inadvertencias, permite alcanzar coherencia y minimiza la dependencia de las posiciones y habilidades adversariales de los abogados y asesores de las partes. ${ }^{72}$ Sin embargo, reiteramos, nuestra descripción se mantiene en el plano positivo y no implica un argumento normativo en favor o en contra de la especialización. Sólo hemos establecido que si un tribunal es técnicamente especializado, probablemente se sentirá menos inclinado a ser deferente con el decisor previo, sin considerar cuán experto este último es.

La discusión previa también se relaciona con el conocido trade-off entre lo que, a partir de la doctrina anglosajona, se conoce como "adjudicación”, por una parte, e "implementación”, por otra. ${ }^{73}$ La tensión

mesurado al impugnar sus educadas profecías y predicciones para el futuro" ( " $[T]$ he court should be very slow to impugn the decisions of fact made by an expert and experienced decision-maker, it must surely be slower to impugn his educated prophesies and predictions for the future"). En política regulatoria: Holder v Law Society [2003] EWCA Civ 39, [2003] 1 WLR 1059. De modo similar, E v SSHD [2004] EWCA Civ 49, [2004] QB 1044, y Unichem v OFT [2005] CAT 8, [2005] 2 All ER 440, at para. 177.

${ }^{71}$ Como analizaremos más adelante, argumentos relativos a la complejidad y tecnicismo de la materia son los que normalmente se recalcan para justificar esta especie de control acotado.

${ }^{72}$ Por todos, S.H. Legomsky, Specialized Justice: Courts, Administrative Tribunals, and a Cross-National Theory of Specialization (Oxford: Clarendon Press, 1990), 22.

${ }^{73}$ Para una de las primeras formulaciones del concepto de adjudicación en el derecho norteamericano, véase Fuller, "The Form" (nota 57). 
existente entre ambas — un problema tradicional del derecho administrativo $-{ }^{74}$ se explica en que cada una de ellas "promueve diferentes valores en el sentido que su racionalidad es dar, respectivamente, con un balance distinto entre intereses sociales e individuales" ${ }^{75}$ En efecto, la aplicación de reglas generales a un caso concreto requiere siempre considerar los valores sociales, intereses y objetivos de esas reglas, por una parte, y los intereses de los individuos sujetos a ellas, por otra. ${ }^{76}$ Lo que se presenta normalmente en una disputa administrativa no es más que un conflicto o tensión entre ambos tipos de intereses, el cual debe ser resuelto en favor de uno u otro grupo. Por una parte, la justicia procesal demanda que el adjudicador sea neutral. Por otra, en cambio, la implementación fuerza al decisor a promover y asegurar objetivos sociales y colectivos que van más allá de los intereses y derechos de aquellos inmediatamente afectados. En otras palaras, el decisor no es neutral, sino una parte interesada en obtener un cierto resultado en términos de política pública. Como bien resume Cane, "la implementación tiende a favorecer la promoción de objetivos sociales, mientras que la adjudicación tiende a favorecer la promoción de intereses individuales". 77

${ }^{74}$ Como J.L. Mashaw, Bureaucratic Justice: Managing Social Security Disability Claims (New Haven, CT: Yale University Press, 1983), 1, resume en su clásico estudio de la materia, "en una cultura legal ampliamente orientada hacia el enforcement de derechos legales individuales en las cortes, 'administración' ha parecido siempre tan contraria a 'derecho' como 'burocracia' lo es a 'justicia'. El derecho se enfoca en derechos, la administración en políticas públicas" ("[i]n a legal culture largely oriented toward court enforcement of individual legal rights, 'administration' has always seemed as antithetical to 'law' as 'bureaucracy' is to 'justice'. Law focuses on rights, administration on policy").

${ }^{75}$ Cane, Administrative Tribunals, 142 (indicando que ambos principios "promueven diferentes valores en el sentido que su racionalidad está dirigida a dar diferentes balances a los intereses sociales e individuales, respectivamente" ("promote different values in the sense that their rationale is to strike respectively different balances between social and individual interests")).

${ }^{76}$ Esta manera de ver las cosas es lo que en el derecho administrativo chileno se denomina "interpretación finalista", y es utilizada por los órganos administrativos al momento de aplicar sus marcos regulatorios. Ella supone reconocer que las normas que habilitan a la intervención de la Administración se dan en contextos sociales dinámicos a los cuales las decisiones de ésta se deben adaptar, intentando garantizar los valores públicos que justificaron el establecimiento de sus competencias públicas. Sobre este criterio, Cordero Vega, Lecciones de derecho, 17 (ver nota 14).

${ }^{77}$ Cane, Administrative Tribunals, 142. 
Lo relevante para nuestra discusión es el efecto que el diseño institucional tiene en la resolución del trade-off entre adjudicación e implementación. Si, como hemos visto, el revisor es técnicamente especializado y, por tanto, en principio menos deferente con el decisor primario, su posición es por diseño más cercana a la de un implementador que a la de un adjudicador común. A su vez, lo contrario puede decirse de un generalista. De aquí que el problema de cómo evitar la interferencia (esto es, cómo dar con el énfasis adecuado para que la revisión no sustituya por completo el juicio del decisor primario) —otro cuestionamiento clásico del derecho administrativo- se vea incrementado en presencia de especialización técnica. Y es en su resolución donde precisamente entra en juego la segunda variable institucional: el espacio que el mismo ordenamiento le atribuye al revisor para tomar sus decisiones. A esto nos abocamos a continuación.

\subsection{Segunda variable: el instrumento y el estándar de revisión}

La segunda variable del diseño institucional dice relación con el estándar de revisión. A diferencia de la variable anterior, que decía relación con los incentivos intrínsecos del revisor derivados de sus capacidades personales y su nivel de "igualdad técnica" respecto del decisor primario, esta segunda variable describe el ámbito de posibilidades que el ordenamiento jurídico le entrega a dicho revisor para desplegar sus capacidades.

En uno de sus extremos, el estándar de revisión puede ser amplio, gozando el revisor de una vasta jurisdicción para tomar parte, por ejemplo, en discusiones complejas acerca de cuestiones económicas o técnicas y desafiar incluso las premisas de la acción del decisor primario. En este extremo, lo que hace el revisor, en la práctica, es examinar lo "correcto" o "incorrecto" de la decisión, esto es, si ella fue "bien" o "mal" adoptada. Este estándar permite la revisión de casi la totalidad de las cuestiones de hecho y de derecho. En el derecho anglosajón se le conoce como "revisión de mérito", y constituye una de las dos opciones de escrutinio judicial consagradas en el derecho inglés y la única existente en el derecho norteamericano. ${ }^{78}$ En el derecho continental, funda-

${ }^{78}$ En este último, véase $\$ 706$ de la Administrative Procedure Act. Para el caso del derecho inglés, véase nota 70 . 
mentalmente francés y español, se le vincula (aunque no corresponde en idéntica equivalencia) a lo que se conoce como revisión de "plena jurisdicción". 79

En el otro extremo se encuentra lo que en terminología inglesa se denomina "revisión judicial" (en sentido restringido o de revisión de formas). Bajo este estándar, el revisor se preocupa esencialmente de la forma en que la decisión ha sido adoptada; es decir, no de la conclusión del proceso y su corrección, sino de si el correcto procedimiento ha sido seguido o, en otras palabras, de la "integridad" de la decisión. En el derecho inglés, por ejemplo, este tipo de revisión pregunta por la "legalidad", "irracionalidad" e "impropiedad procedimental" de la actuación administrativa, de las cuales la segunda es la más relevante (y controversial). ${ }^{80} \mathrm{La}$ irracionalidad implica evitar la discreción absoluta y desatada; esto es, en nuestro propio lenguaje jurídico, impedir las discriminaciones arbitrarias o la ausencia de motivación suficiente. ${ }^{81}$

Con todo, la distinción debe entenderse más como una cuestión de grado que de categorización. Toda revisión es, en alguna medida, una revisión del mérito, especialmente cuando lo que se controla son atribuciones discrecionales del decisor primario, porque es inevitable la revisión de los hechos del expediente administrativo. En este sentido, quizás resulta más adecuado aplicar nuevamente la aludida nomenclatura de "deferencia" versus "no-deferencia", la cual, aunque no hace alusión a un estándar propiamente tal (no existe un "estándar de deferencia", por ejemplo), enfatiza correctamente esta idea. Lo importante es clarificar en qué lugar, dentro de este continuum, se encuentra demarcada la frontera de posibilidades entregadas al juzgador/

${ }^{79}$ El contencioso de plena jurisdicción tiene por finalidad accionar en contra de un organismo de la Administración para el restablecimiento o compensación de un derecho afectado, de manera que, además de la nulidad del acto administrativo, es posible pronunciarse sobre la compensación económica al afectado, así como obligar a la Administración a adoptar medidas concretas con el objeto de proteger o restablecer una situación jurídica concreta. Se denomina contencioso de plena jurisdicción porque el juez tiene competencias completas de revisión de los hechos y el derecho para juzgar el actuar de la Administración. Ver J. Waline, Droit Administratif, 22ª ed. (París: Dalloz, 2008), 588.

${ }^{80}$ Véase Craig, Administrative Law (ver nota 66); J. Arancibia, Judicial Review of Commercial Regulation (New York: Oxford University Press, 2011).

${ }^{81}$ Cordero Vega, Lecciones de derecho, 424 (ver nota 14). 
revisor. ${ }^{82}$ En otras palabras, lo relevante es encontrar cuál es el estándar de revisión aplicable, qué argumentos normativos sirven de base al estándar escogido, y cuál es el test legal utilizado para determinar el cumplimiento con dicho estándar.

El ámbito entregado al revisor para desplegar sus facultades es definido por el propio ordenamiento jurídico. Por ejemplo, en el derecho inglés, el Competition Appeal Tribunal (CAT) - tribunal especializado encargado de la revisión de decisiones primarias adoptadas por agencias en ciertas materias regulatorias y de libre competencia- posee facultades para realizar revisiones de mérito o sólo judiciales (en sentido estricto) de las decisiones, dependiendo del área de que se trate. ${ }^{83}$ Asimismo, el Tratado de la Unión Europea permite que una regulación confiera "jurisdicción ilimitada" a la Corte Europea de Justicia para revisar la imposición de multas en una determinada materia, lo que, de concretarse, implica no sólo permitirle anular la decisión, sino también incrementar o reducir a su solo criterio el monto impuesto. ${ }^{84}$ En el derecho chileno, como en los demás sistemas basados en el derecho continental, este continuo se expresa en la posibilidad que entregan los diversos recursos judiciales para llevar a efecto la revisión con un mayor o menor ámbito de intrusividad. Así, el recurso de apelación —el recurso jerárquico por

${ }^{82}$ El debate respecto de la frontera en materia del estándar de revisión judicial es de larga data en el derecho comparado. Entre otros, véase Breyer et al., en nota 69; Sir J.L. Jowell, A.P. Le Sueur, S.A. de Smith, Lord H. Woolf \& T. Tridimas, De Smith, Woolf and Jowell's Principles of Judicial Review (London: Sweet \& Maxwell, 1999); J. Landis, The Administrative Process (New Haven, CT: Yale University Press, 1938). En Chile, véase L. Cordero Vega, "Entre la deferencia y los estándares de control judicial”, Revista de Derecho Público 68 (2005).

${ }^{83}$ El CAT fue creado con estas funciones por la Enterprise Act 2002. El ámbito de sus competencias está dado, además de esta ley, por normativas sectoriales en materia de energía y telecomunicaciones.

${ }^{84} \mathrm{El}$ artículo 261 TFEU indica que "las regulaciones adoptadas de manera conjunta por el Parlamento Europeo y el Consejo, y por el Consejo, en base a lo dispuesto en los Tratados, podrán conferir a la Corte de Justicia de la Unión Europea jurisdicción ilimitada en relación a las multas contempladas en tales regulaciones" ("Regulations adopted jointly by the European Parliament and the Council, and by the Council, pursuant to the provisions of the Treaties, may give the Court of Justice of the European Union unlimited jurisdiction with regard to the penalties provided for in such regulations"). La jurisdicción ilimitada es, en otras palabras, no sólo un control de legalidad de la sanción pecuniaria, sino también un control de su mérito, por lo que está permitido a la Corte substituir la decisión de la Comisión por la suya propia. Un área donde se ha conferido esta jurisdicción es en materia de competencia (véase artículo 31 de la Regulación No. 1/2003). 
excelencia - "supone que el Tribunal que conoce de él puede revisar los hechos y el derecho de acuerdo con las peticiones concretas formuladas por las partes al interponerlo, con muy pocas limitaciones" ${ }^{85}$ Por el contrario, como es sabido, en los recursos de casación (de forma y fondo) y de nulidad está vedado modificar los hechos. ${ }^{86}$

\subsection{La vinculación de las variables y sus consecuencias}

Como hemos adelantado, en nuestra opinión la clave del diseño institucional en materia de escrutinio judicial radica en que el estándar de revisión debiera ser diseñado "a la medida" de la naturaleza del órgano revisor, dados los incentivos que genera dicha naturaleza. De este modo, si el revisor es generalista y, por tanto, tiene un incentivo a ser deferente con la Administración cuando se trate de revisar ciertos temas, en principio el estándar de revisión no debiera permitirle ir más allá de las cuestiones de derecho, como una forma de restringir la "tentación" de desviarse de dicha deferencia. En caso contrario, el resultado podría resultar dañino para los objetivos que el sistema regulatorio persigue $\mathrm{y}$, particularmente, para efectos de mantener una adecuada consistencia regulatoria. ${ }^{87}$

La situación es exactamente la contraria en el caso de un órgano revisor especializado de carácter técnico en un área determinada. Éste

${ }^{85}$ M. Mosquera \& C. Maturana, Los recursos procesales, $2^{\text {a }}$ ed. (Santiago: Editorial Jurídica de Chile, 2012), 127. La causal genérica que fundamenta la interposición de este recurso es el "agravio", el cual se produce "con motivo de no haber obtenido la parte que impugnaba todo lo que pretendía dentro del proceso" (ibídem, 138).

${ }^{86}$ En este sentido, el artículo $21^{\circ} \mathrm{B}$ del Decreto $\mathrm{N}^{\mathrm{o}} 2.421$, que fija el texto refundido de la ley de organización y atribuciones de la Contraloría General de la República, indica expresamente: "La Contraloría General, con motivo del control de legalidad o de las auditorías, no podrá evaluar los aspectos de mérito o de conveniencia de las decisiones políticas o administrativas".

${ }^{87}$ Nótese que la consistencia regulatoria puede incluso ser ideológica. La actuación de las agencias suelen exhibir consistencia con las ideas del gobierno de turno en una determinada materia: más conservadoras en el caso de gobiernos de derecha, y más liberales en el caso de gobiernos de izquierda (en este sentido, Stephenson, "Statutory", 293). Esto es especialmente plausible en el caso chileno, donde las agencias sectoriales carecen de independencia (salvo el caso de la agencia de competencia) y están por tanto sujetas a un control centralizado por parte del poder ejecutivo. Si el argumento es cierto, constituye una razón por la cual un revisor generalista no debiera ir en contra de las políticas públicas democráticamente fundamentadas. 
tiene escasos incentivos a ser deferente con la Administración, pues - como hemos visto - su propio conocimiento (ya sea acumulado en el tiempo o adquirido por conocimientos en una determinada ciencia o arte) le permite examinar, con confianza y proveyendo fundamentos adecuados, no sólo el derecho, sino también cuestiones de hecho y de política. El estándar, en este caso, debiera ser compatible con dichas capacidades. Si es restringido, en cambio, no parece que hubiera existido razón alguna para crear un organismo de tal naturaleza en primer lugar, pues se perderían los beneficios de la especialización técnica.

Para mostrar esto, es necesario revisar con algo más de profundidad, primero, cómo las decisiones y preferencias del revisor afectan en concreto al decisor primario y, luego, cuál es la relación sistémica entre ambos que surge como consecuencia de su interacción.

\subsubsection{Las variables institucionales y el comportamiento del decisor: ¿Cómo afecta la especialización el resultado de la regulación?}

La revisión ex post que realiza otro organismo ejerce una poderosa influencia en las decisiones ex ante adoptadas por el decisor primario. Para que esto ocurra, no es ni siquiera necesario que el revisor falle en contra del decisor primario de manera muy frecuente. ${ }^{88}$ La razón es sencilla. Es posible presumir que, dependiendo de las específicas características institucionales del revisor, el decisor primario en ciertos casos puede anticipar — en buena medida — los posibles resultados de la revisión. ${ }^{89} \mathrm{Si}$ es racional, el resultado que produzca estará motivado por el deseo de evitar reveses, con el doble objetivo último de, primero, evitar que el organismo revisor dicte una regla que pueda implicarle un ámbito más restrictivo de actuación y, segundo, evitar incurrir en los costos de arribar a una nueva interpretación aceptable para el revisor. Asimismo, asociado a un revés, existe un componente de "vergüenza" institucional y de señalización de que un mayor grado de monitoreo de las actividades del decisor es necesario, cuestiones que éste deseará por cierto evitar.

${ }^{88}$ B. Canes-Wrone, "Bureaucratic Discretion and the Composition of Lower Courts", American Journal of Political Sciences 47, n. 2 (2003): 205-14.

${ }^{89}$ En contra, C. Graham, Regulating Public Utilities: A Constitutional Approach (Oxford: Hart Publishing, 2000), 75 (indicando que "es difícil predecir el resultado de un caso de revisión judicial"). 
Para apreciar mejor esta idea es necesario analizar cómo el decisor primario adopta sus decisiones y cuál es el contenido de ellas. Ante todo, el ámbito en el cual el decisor primario puede desplegar sus poderes está tradicionalmente asociado a límites internos y externos. El límite interno determinado por la sujeción al principio de juridicidad..$^{90} \mathrm{El}$ límite externo, en tanto, está vinculado al principio del control. Implica que, durante el proceso de escrutinio, al ejercer diversos niveles de intervención sobre el ejercicio de las facultades legales y el espacio de discreción del órgano decisor, el revisor delimita el ámbito de actuación de este último. De aquí que los tribunales tengan una influencia crítica en cómo actúan los organismos regulatorios decisores. La cuestión central deviene en establecer cuándo, cómo y en qué medida el organismo revisor aceptará la decisión del organismo primario cuando esta última es distinta de la que aquél hubiese aplicado en el caso concreto. ${ }^{91}$

Supongamos que el decisor enfrenta opciones discretas (digamos, $\mathrm{X}_{1}$ o $\mathrm{X}_{2}$ ) y debe decidir entre ellas. Asumamos además que $\mathrm{X}_{1}$ maximiza un determinado objetivo (por ejemplo, la eficiencia económica o el medio ambiente libre de contaminación) y $\mathrm{X}_{2}$, otro cualquiera diferente del anterior. ${ }^{92}$ Ambas opciones representan el ámbito del derecho. Den-

${ }^{90}$ Conocido tradicionalmente como "principio de legalidad". Sobre este principio, véase: I. de Otto, Derecho constitucional. Sistema de fuentes (Barcelona: Ariel, 1995), 157-58; A. Muñoz Machado, Tratado de derecho administrativo $y$ derecho público general, T.I. (Madrid: Civitas, 2004), 394; O. Oelckers Camus, "El contenido y alcance del principio de legalidad de las actuaciones de la administración del Estado", en La administración del Estado de Chile. Decenio 1990 - 2000, coordinado por R. Pantoja (Santiago: Editorial Jurídica Conosur, 2000), 455.

${ }^{91}$ Stephenson, "Statutory", 306.

92 Para estos efectos asumiremos que el decisor actúa respetando los límites exógenos establecidos por la legislación. El caso indicado en el texto principal dice relación con la multiplicidad de objetivos establecidos en la ley. El derecho de la competencia provee un buen ejemplo: no es extraño que la historia legislativa, la propia ley o el desarrollo jurisprudencial haga referencia, directa o indirecta, a objetivos muy diversos, tales como que la ley incrementará la eficiencia económica, reducirá costos, aumentará la productividad, aumentará las oportunidades para pequeños y medianos empresarios, incrementará el bienestar de grupos históricamente menos aventajados o incluso promoverá el desarrollo de un ambiente políticoeconómico más igualitario (en este sentido, Kovacic, "Institutional Design", 2167). Un ejemplo lo provee el artículo $2^{\circ}$ de la Ley de Competencia Sudafricana (actualmente, Competition Act 89 of 1998, as amended), que enlista objetivos potencialmente disímiles, como la protección de la eficiencia y la protección de la pequeña y mediana empresa. 
tro de él, el contenido de ambas opciones puede variar, tanto en los hechos como en la política. Esto es, cada decisión $\mathrm{X}_{1} \mathrm{y}_{2}$, independiente del objetivo que maximiza, contiene una subdecisión dentro del espacio factual más una dirección que el decisor desea seguir para alcanzar el objetivo. ${ }^{93}$ En términos generales, el decisor tiene una libertad relativamente amplia para decidir tanto por una u otra opción como por el contenido de cada una de ellas. Esto por cuanto existen diversas fuentes en las cuales basar la decisión de derecho (diversos precedentes, diversos principios cuando estos no son explicitados en la legislación, etcétera), diversas formas en las cuales la norma ha sido redactada (usando imperativos o dejando opciones abiertas) o distintas formas de categorizar el objetivo (como primario o secundario, dando especificaciones para llegar a él, etcétera). Todos estos aspectos afectan la decisión que el regulador hará respecto de la decisión de derecho $\left(\mathrm{X}_{1} \mathrm{o} \mathrm{X}_{2}\right)$ y la o las subdecisiones secundarias.

Veamos esto para el caso de un revisor especializado y uno generalista, comenzando por este último. Dado que un revisor no especializado tendrá un incentivo a examinar sólo una parte de la decisión primaria (nuevamente: que el derecho cumpla con el objetivo que debe ser buscado de acuerdo al marco regulatorio), el resultado de la revisión aparece como relativamente claro: o el revisor confirmará la decisión si la opción maximiza el objetivo, o la revertirá si no lo hace. El decisor primario, anticipando este resultado, seguirá ciertas reglas (normalmente procedimentales) y utilizará algunos mecanismos (como guías u otros) para disminuir la probabilidad de que su decisión sea revertida. De aquí que el mayor peligro de la aproximación deferencial es que puede llevar a un excesivo énfasis en aspectos formales de procedimiento. Por cierto, si esto es considerado por sí mismo podría no ser un peligro e incluso ser una ventaja del sistema. Sin embargo, la preferencia por el procedimiento puede bien ser llevada a cabo a expensas de los aspectos sustantivos (especialmente si ambos son substitutos). ${ }^{94}$ La deferencia

${ }^{93}$ Cada una de las cuales colabora individualmente al proceso de maximización.

${ }^{94}$ Véase M.C. Stephenson, "The Strategic Substitution Effect: Textual Plausibility, Procedural Formality, and Judicial Review of Agency Statutory Interpretations”, Harvard Law Review 120 (2006): 528. En página 530, nota 2, dice: “... incrementar la formalidad procedimental hace decrecer el beneficio marginal de la corte de imponer un estándar más exigente de revisión sustantiva, mientras que una 
excesiva bien puede invitar al regulador a no proveer de razones para sus decisiones, sino simplemente a indicarlas para prevenir recursos en su contra. Asumiendo que tampoco existe un deber fuerte de justificación o que éste no suele ser exigible (como ocurre, por ejemplo, en el caso chileno), no existe un incentivo a explicar la decisión de manera detallada ni a proveer de criterios claros. La deferencia implica, para el regulador, que mientras más robusto sea su procedimiento para llegar a la decisión, más segura será su posición frente el órgano revisor, sin considerar los aspectos sustantivos. ${ }^{95}$

Por el contrario, el resultado no es claro cuando el revisor es especializado técnico. Como este último no sólo analizará la decisión de derecho, sino también las subdecisiones, el decisor primario no puede anticipar si aquél estará de acuerdo con el hecho que, siguiendo ciertos "pasos" el objetivo será maximizado. El motivo está en la naturaleza de la revisión. Mientras el examen del derecho (de una regla o principio regulatorio) es relativamente simple desde una perspectiva ex ante, el examen de los hechos y las políticas implica un espacio de discreción mucho mayor. Por tanto, un revisor especializado puede llegar a la conclusión de que los hechos, el derecho o la política, dos de ellos, o todos, no permiten maximizar el objetivo buscado. El peligro central de la especialización técnica, entonces, radica en la posibilidad de que la Ad-

$\overline{\text { decisión de la agencia de disminuir su nivel de formalidad procedimental incremen- }}$ ta el beneficio marginal de la corte de imponer un estándar sustantivo más exigente" ("...increasing agency procedural formality decreases the marginal benefit to the court of a more stringent standard of substantive review, while an agency's decision to decrease its level of procedural formality increases the marginal benefit to the court of a more stringent substantive standard"). De modo similar se expresan R. Baldwin \& C. McCrudden, Regulation and Public Law (London: Weidenfeld and Nicolson, 1987), 60-63, donde indican potenciales consecuencias adversas de la revisión judicial. Una respuesta a esto en el derecho europeo es lo que se conoce como curative principle o el "derecho a una jurisdicción completa" consagrado en el artículo 6(1) de la Convención Europea de Derechos Humanos. De acuerdo a éste, cuando un organismo decisor no cumple con las características listadas en dicho artículo (fundamentalmente, independencia e imparcialidad), debe existir el derecho a que la disputa en cuestión sea llevada ante un tribunal con "jurisdicción completa", de modo que el defecto en el decisor primario quede "curado". Un tratamiento de este tema en Arancibia, Judicial Review, 118 y ss. En el derecho chileno, el Tribunal Constitucional ha fallado sobre bases similares en STC rol 2529-13, de 02 de enero de 2015.

${ }^{95} \mathrm{~A} \mathrm{su}$ vez, el énfasis en procedimiento bien puede llevar a ineficientes demoras. 
ministración se transforme en un mero "compilador de hechos"; en una instancia formal que sólo es considerada - en el extremo- como un paso previo necesario para arribar al revisor, que pasa a ser el verdadero decisor de la cuestión sometida a su conocimiento.

Todo lo anterior ha sido resumido por un autor de un modo bastante preciso: para los reguladores, esto refleja "una cruda ecuación: revisión de expertos por generalistas — amplio margen de apreciación; revisión de expertos por otros expertos (potencialmente incluso 'expertos más expertos') — estrecho margen". 96

\subsubsection{Consecuencias sistémicas}

La relación entre decisor primario y revisor (o, en otras palabras, la vinculación entre variables institucionales) en las diversas jurisdicciones, da lugar a divergentes concepciones sistémicas. Considérese, por ejemplo, Estados Unidos y el Reino Unido. Mientras en el primero la relación es cercana al "antagonismo", en el sentido de la existencia de una cierta tensión entre el revisor y el decisor, en el segundo la relación es "armónica", en el sentido que es expresión de una división relativamente clara de los roles entre uno y otro. ${ }^{97}$ Ciertamente, esta cuestión depende de las condiciones institucionales locales, pero también es una manifestación de un debate más profundo del sistema institucional considerado como un todo.

En efecto, la discusión anterior está en el corazón de una más general acerca de la relación constitucional entre los poderes del Estado, la cual implica supuestos fundamentales acerca del rol (en sentido amplio) que debe cumplir la judicatura en el proceso regulatorio (algo que podríamos llamar el "viejo dilema" imperante desde la introducción del sistema liberal). Dado que un estándar de revisión amplio implica una mayor reducción de la autonomía de la Administración, esto podría llegar a contrariar la mencionada visión de que corresponde a la Ad-

96 T. de la Mare, "Regulatory Judicial Review: The Impact of Competition Law" (paper presentado en la conferencia ALBA 2007), disponible en: http:/www. adminlaw.org.uk/docs/Thomas\%20de\%201a\%20Mare\%20-\%20June\%202007.pdf/ (último acceso: 29 abril 2014).

${ }^{97} \mathrm{D}$. Mantzari, Appeals from Utilities Regulators in the US and the UK: What Are the Limits of Judicial Review of Economic Evidence?, tesis doctoral (2014), University College London, 166 y ss. 
ministración, no al juez, efectuar el balance entre derechos privados y necesidades públicas. ${ }^{98}$ Desde esta perspectiva, cualquier movimiento tendiente a un mayor activismo judicial ${ }^{99} \mathrm{o}$, en términos menos fuertes, un enfoque relativamente más intrusivo por parte de las cortes generalistas, siempre representará una concepción algo diferente de la separación de poderes y, en cuanto tal, debe estar fundada en sólidas razones aceptadas por la constitución. Aceptar mayores espacios de discrecionalidad administrativa implica, por cierto, que el propio diseño institucional provee de soluciones adecuadas y suficientes para los problemas públicos, de modo que la actuación judicial (sustantiva) no puede ser plenamente justificada en el principio de inexcusabilidad. Dado que éste es un supuesto fuerte y controvertido, incentiva a una menor deferencia cuando el ordenamiento jurídico da las posibilidades para ello.

Por el contrario, un estándar restrictivo, que restrinja al juez, puede llegar a ser inconsistente con la visión que las propias cortes tienen de su rol dentro del orden fundamental. La visión del juez como controlador por esencia de los actos de la Administración (o de una Administración limitada) y protector por esencia de las garantías individuales implica dotarlo, independiente de sus capacidades intrínsecas, de un mayor espacio de determinación y establecimiento de estándares en cuestiones de derecho y política. ${ }^{100}$ Estas cuestiones exceden los límites autoimpuestos en este trabajo, pero deben tenerse en consideración, por cierto, al diseñar cada una de las partes del sistema.

98 Véase sección 2.1.1.

${ }^{99}$ En el derecho chileno, J.F. García y S. Verdugo han argumentado que estaríamos en presencia de activismo judicial. Ver su Activismo judicial en Chile ¿Hacia el gobierno de los jueces? (Santiago: Ediciones L\&D, 2013).

${ }^{100} \mathrm{El}$ caso chileno es interesante. Al carecer de un sistema regular de impugnaciones contenciosas administrativas, se ha hecho uso del recurso de protección (una acción cautelar de derechos fundamentales indubitados) como un medio regular para resolver problemas sobre la nulidad de actos administrativos. Al utilizar esta acción, el sistema institucional chileno "fundamentalizó" todos los conflictos entre el Estado y los particulares (atendido que se trataba de una cuestión de procesabilidad necesaria) $y$, en consecuencia, los jueces utilizaron herramientas propias de la tutela de derechos fundamentales para dar soluciones de nulidad de actos. La consecuencia de esto es que la revisión judicial por este medio se ha prestado para soluciones de equidad, con todas las consecuencias que ello implica para un sistema de revisión de agencias especializadas. Véase, en este sentido, Cordero Vega, Lecciones de derecho, 423 (ver nota 14); y J.C. Ferrada, "El recurso de protección como mecanismo de control", en La justicia administrativa (Santiago: Lexis Nexis, 2005). 


\section{ILUSTRANDO LA TEORÍA: EL MODELO INSTITUCIONAL CHILENO EN MATERIA DE LIBRE COMPETENCIA Y MEDIO AMBIENTE}

Todo el marco teórico expuesto en la parte 2 puede ser ilustrado con dos ejemplos provenientes de la legislación chilena: la libre competencia y la protección del medio ambiente. Desde un punto de vista institucional, ambos presentan tanto similitudes como diferencias importantes. Entre las primeras destacan tres. Primero, ambas áreas se caracterizan por estar basadas en la especialización desde una perspectiva jurisdiccional, es decir, en la experticia o experiencia dedicadas a un ámbito del saber específico. ${ }^{101}$ Segundo, la especialización en estas áreas coincide, además, con el elemento subjetivo de la definición que utilizamos en este trabajo. Ambos sistemas están fundados en un esquema dual, basado entre un organismo administrativo y tribunales técnicos: la Fiscalía Nacional Económica (FNE) y el Tribunal de Defensa de la Libre Competencia (TDLC), en materia de competencia, y la Superintendencia del Medio Ambiente (SMA) y tres Tribunales Medio Ambientales (TMA), en materia medio ambiental. Mientras el TDLC está compuesto por dos economistas y tres abogados con experticia en materias de competencia, ${ }^{102}$ los TMA están cada uno integrados por dos abogados y un licenciado en ciencias con especialización en materias medioambientales. ${ }^{103}$ Tercero, en ambos sectores el ámbito de competencia de los organismos abarca todos los mercados. En esto se diferencian de otros organismos administrativos regulatorios chilenos, como la Subsecretaría de Telecomunicaciones (Subtel), la Superintendencia de Electricidad y Combustibles (SEC) o la Superintendencia de Servicios Sanitarios (SISS), que tienen a su cargo primordialmente la fiscalización y cierta regulación de sectores específicos. ${ }^{104}$

101 Véase sección 2.1.1. En ambas áreas la tendencia a la especialización es mundial. En medio ambiente, véase B.J. Preston, "Charasteristics of Successful Environmental Courts and Tribunals", Journal of Environmental Law 26, n. 3 (2014): 365-393; en libre competencia, I. Lianos, La transformation du droit de la concurrence par le recours à l'analyse économique (Bruselas: Bruylant; Atenas: Ant. N. Sakkoulas, 2007).

102 D.L. N. ${ }^{\circ} 211$, artículo 6.

${ }^{103}$ Ley N. ${ }^{\circ} 20.600$, artículo 2.

104 Además de las similitudes mencionadas en el texto central, tanto la FNE como la SMA tienen asignado un rol de promotor de sus respectivas materias. 
Aunque estas similitudes (en particular su carácter especializado) son las que suelen destacarse en las descripciones generales de ambos sistemas, son las diferencias las que resultan más relevantes para nuestros propósitos. Éstas se resumen en que mientras el sistema medioambiental descansa en un modelo inquisitivo, en el cual la decisión de fiscalizar y sancionar es de la agencia - la SMA-, dejando la intervención judicial de los TMA para la revisión, el de libre competencia lo hace en uno "acusatorio" o de promoción de parte, quedando la potestad de sancionar subordinada a la decisión del tribunal especializado —el TDLC — al cual la agencia — la FNE — presenta su caso (bajo la ficción legal de que esta última actúa como "una parte más" dentro del proceso). Considerando estas cuestiones, en lo que sigue esta sección, primero, analiza brevemente las razones que explican tanto la introducción de especialización en la legislación chilena como la forma en que ella ha sido incorporada en estas áreas (3.1); y, segundo, centra la discusión en la revisión judicial realizada por la Corte Suprema en ambos sistemas (3.2).

\subsection{El diseño institucional, la introducción de especialización y la toma de decisiones en materia medioambiental y de libre competencia}

\subsubsection{Origenes}

La introducción de especialización en ambos sistemas, de libre competencia y medioambiental, está marcada por un aspecto subyacente de orden más general: la realidad histórica que llevó a la formación del Estado administrativo chileno actual. Como ha sido destacado por varios comentaristas, su característica central es la ausencia de un sistema de justicia administrativa destinado específicamente a resolver conflictos entre la Administración y particulares, aplicable de modo general a los distintos sistemas públicos de derecho. ${ }^{105}$ Localmente, la introducción de justicia especializada técnica se vincula, en cierta medida, con la ausencia de tal sistema ${ }^{106}$ y la desconfianza en la Administración instalada luego de los excesos cometidos por ésta en el pasado. Esta situación propició las condiciones para el crecimiento de un

${ }^{105}$ Véase Ferrada, "Justicia administrativa” (ver nota 3).

106 Ídem. 
sistema desintegrado e inorgánico, con competencias parceladas; el que en cierta medida resulta inadecuado para hacer frente al mayor ámbito de acción de la Administración que, como hemos indicado, se ha venido desarrollando desde principios del siglo XX.

A consecuencia de lo anterior, las escasas menciones al diseño institucional en el derecho chileno han estado centradas casi exclusivamente, por una parte, en los aspectos orgánicos (en particular, en la idea de justicia procesal — procedural fairness — ${ }^{107} \mathrm{y}$ fundamentalmente la independencia del decisor primario); y, por otra, en la separación vertical de competencias, esto es, la cuestión procesal respecto de quién toma las decisiones políticas y regulatorias. Como veremos, mientras el primer aspecto fue fundamental en la creación del actual régimen de libre competencia, la discusión sobre si el óptimo está dado por el establecimiento de un sistema unificado de toma de decisiones (el sistema administrativo clásico) o por uno donde los poderes y facultades de investigación y persecución estén separados de la decisión ${ }^{108}$ fue fundamental al crear el sistema ambiental. En ambos casos, la especialización fue introducida sólo de manera secundaria, a pesar de que, según hemos sostenido, ella debiera ser la variable crucial al diseñar un sistema, por cuanto es la única que tiene un real impacto significativo en los incentivos y decisiones del revisor. ${ }^{109}$

En efecto, en el sistema chileno de defensa de la libre competencia, al momento de crearse el TDLC el modelo orgánico de toma de decisiones primarias existente ya se basaba en un sistema dual. Mientras la FNE poseía roles similares a los actuales (básicamente, investigación y persecución de conductas anticompetitivas), la decisión primaria de un caso estaba entregada a las llamadas "comisiones", las cuales tenían además otras variadas competencias decisorias y regulatorias dentro del área. Desde el punto de vista del diseño institucional, este modelo era orgánicamente "informal": las comisiones (particularmente la Comisión

107 Sobre este concepto, véase nota 24 y el texto principal al cual acompaña.

108 Sobre la separación, véase A. Galetovic \& R. Sanhueza, "Regulación de servicios públicos: ¿Hacia dónde debemos ir?”, Estudios Públicos 85 (2002): 101-137. Como es sabido, los sistemas administrativos clásicos siguen el primer modelo, que es lo que en el derecho chileno se ha venido a consagrar como "superintendencias" sectoriales. Sobre cómo avanzar hacia otro modelo de agencias independientes, véase Cordero \& García, "Elementos para la discusión” (ver nota 45).

${ }^{109}$ Ver sección 2.1. 
Resolutiva, la principal de ellas) no sólo carecían de integrantes permanentes y expertos en libre competencia, sino que compartían recursos humanos con la FNE y dependían, en gran medida, de los insumos que ésta les entregara. En este contexto, los cuestionamientos tanto a la independencia de las comisiones como a la escasa profundidad de sus decisiones eran evidentes y fueron paulatinamente crecientes. De aquí que en el actual modelo, introducido en el año 2003, la decisión primaria y la eventual imposición de sanciones pasara a manos de un "tribunal" (el TDLC), con el fin último de dotar al sistema principalmente de un mayor nivel de justicia procesal. La independencia constituyó el leimotiv de la reforma. ${ }^{110}$ En este contexto, la incorporación de expertise económico dentro del proceso fue - como hemos indicado- secundaria, y debe necesariamente ser entendida en ese marco. Lo esperado era que tal expertise contribuyera a simplificar y "abaratar" la acción de la FNE, promoviendo así un uso más eficiente de los recursos, y llevase a decisiones basadas en reglas económicas más simples y directas, mediante el uso de presunciones u otros criterios objetivos de decisión. ${ }^{111}$

La situación no fue muy distinta en materia medioambiental. A diferencia de la libre competencia, la protección del medioambiente siempre estuvo encargada a un solo organismo, llamado Comisión Nacional del Medio Ambiente o Conama. Se trataba de un servicio descentralizado, cuya máxima autoridad era un consejo directivo integrado por 13 ministros de Estado. Esta estructura reconocía el carácter

${ }^{110}$ Antecedentes legislativos y anecdóticos relativos a la reforma que culminó en la creación del TDLC en el año 2003 confirman este punto. Por ejemplo, en el mensaje con que fue enviado el proyecto al Congreso se indica expresamente que las antiguas comisiones "no cumplen requisitos básicos de independencia, especialidad, dedicación y dotación de recursos" (el destacado es nuestro). La independencia buscada se refería tanto respecto de la FNE (organismo que, a su vez, carecía de independencia en esos tiempos) como respecto del poder ejecutivo. Véase Historia de la Ley $N^{\circ}$ 19.911. Crea el Tribunal de Defensa de la Libre Competencia (http://www.leychile.cl/Navegar/scripts/obtienearchivo?id=recursoslegal es/10221.3/2472/1/HL19911.pdf/), 5 y 7. En otros lugares de la historia legislativa se resalta asimismo la imparcialidad. Además, conversaciones informales con diversos actores participantes del proceso nos han ratificado que el foco central de la modificación estuvo en aumentar la independencia.

111 Para una crítica indicando que este objetivo no se cumplió durante los primeros diez años del TDLC, véase J. Tapia, “'Dime de qué presumes y te diré de qué careces': el tratamiento jurisprudencial de los abusos de dominancia en Chile", Revista de Derecho de la Competencia CEDEC XIV 10, n. ${ }^{\circ} 10$ (2014). 
interdisciplinario del tema y confería, en teoría, un rol activo a cada ministerio en la formulación de las políticas ambientales. Sin embargo, se trataba fundamentalmente de un organismo coordinador, cuya estructura orgánica no permitía dar al desarrollo de una política ambiental la preponderancia adecuada dentro del aparato estatal. De aquí que el propósito central de la reforma que creó la actual institucionalidad buscara primordialmente desintegrar verticalmente las competencias, separando la creación e implementación de políticas sectoriales (en manos del Ministerio de Medio Ambiente) de la gestión (a cargo del Servicio de Evaluación Ambiental) y de la triple función de investigación, persecución y decisión/sanción (encargada a la Superintendencia del Medio Ambiente, SMA). ${ }^{112}$

En este último caso, el proyecto original pretendía la creación de un régimen administrativo tradicional, de acuerdo al cual la SMA sería un organismo motivado por el diseño e implementación de políticas sectoriales, y que tendría además la facultad de determinar infracciones a la ley sustantiva sectorial e imponer multas a los agentes que las cometieran. En su concepción original, la decisión primaria, adoptada por la SMA (una agencia con competencias inquisitivas), el Servicio de Evaluación Ambiental (una agencia a cargo de un procedimiento administrativo autorizatorio) o el Ministerio del Medio Ambiente (a cargo de la regulación normativa técnica), sería luego revisada judicialmente por una corte de tipo generalista. ${ }^{113}$ Sin embargo, al igual que en materia de libre competencia, la especialización fue introducida sólo de manera secundaria al sistema. ${ }^{114}$ En efecto, la positiva experiencia percibida por

112 Un análisis del modelo en D. Hervé, M. Guiloff \& R. Pérez, eds., Reforma a la institucionalidad ambiental: antecedentes y fundamentos (Santiago: Ediciones UDP, 2010).

113 Así lo indicaba el artículo 55 del proyecto original, que establecía una "reclamación" ante la Corte de Apelaciones. El artículo 56, por su parte, contemplaba la posibilidad de apelar ante la Corte Suprema. Véase Historia de la Ley $N^{o}$ 20.417. Crea el Ministerio, el Servicio de Evaluación Ambiental y la Superintendencia del Medio Ambiente" (http://www.bcn.cl/obtienearchivo?id=recursoslegal es/10221.3/3929/6/HL20417.pdf/), 52.

114 Siguiendo lo que la doctrina denomina "isomorfismo institucional"; esto es, el proceso por el cual una unidad de un conjunto comienza a parecerse a otras que enfrentan condiciones similares. Véase P.J. DiMaggio \& W. Powell, “"The Iron Cage Revisited': Institutional Isomorphism and Collective Rationality in Organizational Fields", American Sociological Review 48 (1983): 147-60. 
el sector privado y el gobierno respecto de las actuaciones del TDLC llevó a modificar el proyecto original y establecer en esta área tribunales de revisión de naturaleza especializada técnica. ${ }^{115}$ De este modo, fue reservada a los TMA una labor de revisión de la legalidad de las decisiones administrativas primarias, es decir, fue establecido un contencioso de nulidad de los actos administrativos ambientales, ${ }^{116}$ pero sujeto a una revisión de jueces especializados en donde lo que se busca es controlar esencialmente la discrecionalidad de la decisión de la autoridad.

De la descripción anterior se sigue que estamos en presencia de dos diseños muy diversos de distribución de poderes entre organismos esta-

${ }^{115}$ La idea de crear tribunales especializados aparece oficialmente por primera vez en la historia legislativa en la intervención del representante de un gremio privado (Historia de la Ley 20.417, 132 (ver nota 113)), luego de lo cual es reiterada por varios parlamentarios y otros actores en distintas instancias. De este debate se da cuenta en la historia de la ley que luego crearía estos tribunales: véase Historia de la Ley $N^{o} 20.600$, 6. Durante la tramitación legislativa, esto se materializó en un protocolo de acuerdo que estableció, en su punto n. ${ }^{\circ}$, "el compromiso de contar con un Tribunal Ambiental [...] que se estructurará sobre la base de los siguientes ejes: (a) El reconocimiento de un organismo jurisdiccional especializado; (b) Integración mixta del tribunal. El tribunal estará compuesto por cinco miembros, de los cuales tres serán abogados y dos profesionales provenientes del área de las ciencias o la economía; (c) Las competencias de este nuevo órgano jurisdiccional serán relativas al contencioso administrativo ambiental, de modo que todas las competencias que en la actualidad entrega la Ley N. ${ }^{\circ} 19.300$ a los tribunales ordinarios pasarán a este tribunal, así como la potestad de revisión de los actos administrativos de la Superintendencia de Medio Ambiente; (d) Tendrá, además, competencias de control previo en el caso de algunas medidas provisionales que pueda decretar la Superintendencia de Medio Ambiente, de revisión plena y obligatoria (consulta) respecto de las sanciones más graves que pueda aplicar la referida Superintendencia, y de competencia plena en el caso del daño ambiental; (e) El tribunal tendrá amplias atribuciones para evaluar la legalidad, proporcionalidad, razonabilidad y contenido técnico de las decisiones objeto de su competencia".

${ }^{116}$ El artículo 17 n. ${ }^{\circ} 8$ inciso segundo de la Ley N. ${ }^{\circ} 20.600$, que crea los Tribunales Ambientales, define el "acto administrativo de carácter ambiental" como "toda decisión formal que emita cualquiera de los organismos de la Administración del Estado mencionados en el inciso segundo del artículo $1^{\circ}$ de la Ley Orgánica Constitucional de Bases Generales de la Administración del Estado, que tenga competencia ambiental y que corresponda a un instrumento de gestión ambiental o se encuentre directamente asociado con uno de estos". A su vez, la Ley N. ${ }^{\circ} 19.300$ sobre Bases Generales del Medio Ambiente, establece como "instrumentos de gestión ambiental", fundamentalmente, las normas de calidad y emisión, la declaración de zonas saturadas o latentes, los planes de prevención o descontaminación y las resoluciones de calificación ambiental. 
tales. Institucionalmente, el medioambiental no es más que un modelo tradicional de derecho administrativo (esto es, un simple contencioso de nulidad en base a organismos con competencias inquisitivas), salvo por el importante hecho que los TMA resultaron finalmente establecidos como órganos especializados de contenido técnico. ${ }^{117}$ El modelo de libre competencia, en cambio, responde a una forma de poder distribuido relativamente inusual en el mundo ${ }^{118}$ y única en Latinoamérica ${ }^{119}$, bajo el cual la decisión es configurada como supuestamente jurisdiccional, adoptada por un organismo judicial especializado. En ambos casos, si bien consecuencialmente, la especialización ha sido elevada a característica central dentro del respectivo sistema institucional.

\subsubsection{El impacto del diseño en la decisión primaria}

La especialización se aviene bien con el hecho que, tanto en materia de libre competencia como de protección medioambiental, existe un amplio espacio para la interpretación discrecional, ya sea por parte de los respectivos decisores primarios (la SMA y el TDLC) o de los revisores (los TMA y la Corte Suprema). Entre las razones centrales está el hecho de que la descripción legal de los actos administrativos ambientales y la de las conductas relacionadas con la libre competencia se caracterizan por ser limitadamente regladas y abundantes en conceptos jurídicos indeterminados. En materia medioambiental, esto se debe al carácter extremadamente fragmentado de la regulación, compuesta por un elevado número de disposiciones legales y basada en una definición de

${ }^{117}$ En esto, el modelo chileno tiene dos grandes influencias. Por una parte, la Ley de Procedimiento Administrativo de los Estados Unidos, en lo que se refiere a los estándares de revisión: ver Administrative Procedure Act, APA, 1946, 5 U.S. Code \$706, scope of review. Por otra parte, la Ley de lo Contencioso Administrativo española, en lo relativo a los límites de los poderes de sustitución del juez contencioso administrativo: ver Ley 29/1998, de 13 de julio, reguladora de la Jurisdicción Contensioso-Administrativa, artículo 71.

118 Tapia \& Montt, "Judicial” (ver nota 23).

119 Desde el año 2011, Brasil cuenta con una institución unificada que incluye tribunales administrativos dentro de la agencia. En el resto de los países latinoamericanos prima un modelo administrativo tradicional, con una agencia que es parte del poder ejecutivo y que puede imponer sanciones, cuyas decisiones son luego revisadas judicialmente. Éste es el sistema imperante, además, en la Unión Europea y en la mayoría de sus Estados miembros. 
acto administrativo con contornos imprecisos, vinculada además a una multiplicidad de "instrumentos de gestión ambiental". ${ }^{120}$ Por su parte, la normativa de libre competencia, si bien es unificada y no fragmentada - al menos en lo que se refiere al derecho como algo distinto de las políticas de libre competencia_- ${ }^{121}$, en el sentido de que la descripción de las conductas en la legislación se encuentra principalmente contenida en una disposición legal dentro de un solo cuerpo normativo, dicha descripción es efectuada de forma abierta, sin objetivos claramente definidos y sobre la base de estándares amplios, no reglas específicas. ${ }^{122}$ De este modo, en ambas áreas es posible desplegar un alto grado de discrecionalidad técnica, la cual, a su vez, incentiva la especialización.

Sin embargo, no obstante estos aspectos comunes, el diseño institucional produce una diferencia sustancial en el rol de los TMA vis-avis el TDLC en lo que respecta al criterio para resolver un determinado caso. Utilizando una reconocida terminología, los TMA son primariamente organismos revisores "adjudicadores", en el sentido de que su raison d'être es la protección de los intereses individuales de quienes resultan sujetos pasivos de las normas ambientales; o, en palabras de la ley, su "función es resolver las controversias medioambientales de su competencia". ${ }^{123}$ El TDLC, en cambio, no es ni un organismo revisor ni adjudicador, sino que su rol fundamental es "implementar" la normativa de competencia; esto es, resolver con un sesgo hacia la promoción de

${ }^{120}$ Véase nota 116.

${ }^{121}$ Ésta no es, por cierto, una característica única en Chile: en todas las demás jurisdicciones que poseen ordenamientos jurídicos protectores de la competencia, el contenido sustancial del derecho es esencialmente casuístico. Y ese contenido sustancial ha alcanzado grandes niveles de consenso mundial en muchos aspectos. Véase, por ejemplo, E. Elhauge \& D. Geradin, Global Antitrust Law and Economics, $2^{\mathrm{a}}$ ed. (New York: Foundation Press, 2011).

122 Por esto, se ha sostenido correctamente que el derecho de la competencia puede ser, alternativamente, expresión del liberalismo de mercado, un instrumento del populismo económico o una política simbólica con un casi nulo impacto económico. Todo depende del objetivo que se busque y de las doctrinas subyacentes imperantes en un momento determinado (en este sentido, Eisner, Antitrust, 229 (ver nota 22)). En sí misma, la libre competencia no es más que es una política en busca de propósito y claridad.

${ }^{123}$ Ley N. $^{\circ} 20.600$ que crea los Tribunales Ambientales, artículo $1^{\circ}$. Esta función es central, sin perjuicio de que, como hemos visto, su especialización los dota de cierta "sensibilidad" más cercana a las políticas de la agencia que la que tendría un órgano revisor generalista. 
los intereses sociales que forman la base de las reglas jurídico-económicas de protección de la libre competencia. ${ }^{124}$

El carácter de implementador del TDLC lo diferencia de otros entes judiciales, comunes y especializados. Por una parte, dicho carácter explica que el TDLC posea algunas facultades ajenas a un tribunal común generalista, tales como las de dictar o proponer normativa regulatoria. ${ }^{125}$ Por otra parte, su rol de implementador lo diferencia también de otros tribunales especializados en libre competencia en el mundo (como el Competition Appeal Tribunal (CAT), del Reino Unido; el Competition Tribunal canadiense; o el Competition Tribunal de Sudáfrica), los cuales, no obstante compartir la característica de especializados, tienen un rol de revisores/adjudicadores y, por ende, una exigencia prima facie de no sustituir la decisión primaria.

La diferencia de énfasis entre darle mayor peso a los aspectos sociales —implementación — o a los individuales — adjudicación — a que da lugar el diseño institucional de libre competencia y medioambiental en Chile, respectivamente, resulta suficiente como para descartar que sea adecuado comparar el rol de los TMA y el TDLC. Por más que en ambos casos se esté en presencia de "tribunales especializados", tal denominación no parece ser más que formal o semántica. ${ }^{126}$ Se trata en realidad de organismos llamados a cumplir roles fundamentalmente diferentes, cada uno dentro de su respectivo entramado institucional. Por tanto, para eva-

${ }^{124}$ En este sentido, nótese que el rol del TDLC no está muy alejado del que cumple un revisor "interno" de la propia agencia, como lo son, por ejemplo, los Tribunales de Derecho Administrativo (Administrative Law Judges o ALJ) del derecho norteamericano, los cuales, aunque están funcionalmente separados de las ramas investigativas y prosecutorias de la agencia, también poseen funciones eminentemente implementativas y no adjudicatorias (Cane, Administrative Tribunals (ver nota 8)).

${ }^{125}$ Como por ejemplo la de "dictar instrucciones de carácter general en conformidad a la ley..." o la de "proponer al Presidente de la República...la modificación o derogación de preceptos legales y reglamentarios..." (D.L. N. ${ }^{\circ} 211$, artículo $18 \mathrm{n} .^{\circ} 3 \mathrm{y} \mathrm{n} .^{\circ} 4$, respectivamente). En ambos casos, es la promoción del interés público el que justifica tales exorbitantes competencias.

${ }^{126}$ Es incluso posible extender el argumento y llegar a negar el carácter de "tribunal" al TDLC. Si la implementación prima independientemente de si se está en presencia de litigación privada o pública (esto es, sin o con presencia de la FNE), los requerimientos de justicia procesal que primaron al momento de la creación del sistema podrían en gran medida no ser tan relevantes producto del propio diseño institucional de "decisión especializada" finalmente escogido. Éste es un argumento que no exploramos en este trabajo. 
luar el diseño institucional chileno en materia de revisión judicial propiamente tal es imprescindible centrar la atención en el rol que ha jugado el verdadero revisor final en ambos casos: la Corte Suprema.

\subsection{La revisión de las decisiones por la Corte Suprema}

A nivel general, la Corte Suprema chilena está cumpliendo un rol cada vez más trascendental para estructurar la interfase entre el Estado y el mercado en diversos sectores económicos. ${ }^{127}$ Con cada vez mayor frecuencia, la Corte define derechos de propiedad, condiciona las formas de organización corporativa, define ámbitos de proyectos y limita las relaciones entre firmas tanto dentro del mercado como fuera de él. Es, en suma, el árbitro final en una serie de controvertidas decisiones regulatorias. Quizás no sea una exageración afirmar que, hoy en día, los límites de los mercados chilenos en sí mismos no son sino el producto de las normas interpretadas por la Corte. ${ }^{128}$ Esto quiere decir que, cada vez más, la Administración ejerce sus facultades dentro del espacio de discrecionalidad definido ya no únicamente por la ley, sino también por la Corte. ${ }^{129}$ El enforcement legal es, entonces, contingente a lo que ésta determine.

Esto se observa con claridad tanto en materia medioambiental como de libre competencia. La pregunta relevante en estos sectores es

${ }^{127}$ El rol central adquirido por los tribunales en materias regulatorias es un fenómeno que trasciende fronteras; incluso más allá del derecho norteamericano y su consabido modelo de "regulación a través de la litigación" (véase K.W. Viscusi, ed., Regulation through Litigation (Washington, DC: Brookings Institution Press, 2002); y D.P. Kessler, ed., Regulation vs. Litigation. Perspectives from Economics and Law (Chicago: The University of Chicago Press, 2011)). En muchos países se preveía que los tribunales serían actores periféricos dentro del Estado regulador y la situación terminó siendo precisamente la contraria. En el Reino Unido, por ejemplo, el agresivo programa privatizador del gobierno conservador, llevado a cabo durante los años 80, anticipaba un rol muy limitado para las cortes (para una explicación detallada, véase J. Black \& P. Muchlinski, "Introduction", en Commercial Regulation and Judicial Review, editado por J. Black, P. Mushlinski \& P. Walker (Oxford: Hart, 1998)).

${ }^{128}$ En el derecho norteamericano, Commons caracterizó a la Corte Suprema de los Estados Unidos como "la primera autoridad competente en materia de política económica" ( "...the first authoritative faculty of political economy"). La frase parece cada vez más cerca de ser totalmente aplicable al caso nacional. Véase J.R. Commons, The Legal Foundations of Capitalism [1924] (Clark, NJ: The Law Book Exchange Ltd., 2012), 7.

${ }^{129}$ Para el caso de medioambiente, véase, en el caso chileno, L. Cordero Vega, "Corte Suprema y medio ambiente: ¿Por qué la Corte está revolucionando la regulación ambiental?", Anuario de Derecho Público 2012, UDP: 339. 
por qué la Corte Suprema ha actuado, en términos generales, de una forma relativamente poco deferente frente a las decisiones de los TMA $\mathrm{y}$ el TDLC, considerando que se trata de un revisor generalista actuando frente a un decisor especializado. Como veremos, la respuesta es, sencillamente, "porque puede", dado el contexto institucional chileno: es éste el que le permite actuar con un escaso grado de deferencia. La razón es que, en nuestro sistema, las dos variables institucionales que hemos definido como centrales (naturaleza del órgano e instrumento de revisión) han sido combinadas de manera inexacta (3.2.1). Esto produce serios peligros para el sistema y dificulta la consecución de los objetivos que se tuvieron en vista al dotar a estas dos áreas del derecho de especialización (3.2.2).

\subsubsection{La interacción de las variables institucionales: los recursos judi- ciales frente a una corte generalista}

La Corte Suprema chilena está compuesta por jueces generalistas viviendo en un "mundo especializado"130 (al menos en las dos áreas analizadas en este trabajo). ${ }^{131}$ Como hemos argumentado, independiente del juicio de valor que pudiera efectuarse respecto de dicha característica, ella debiera prima facie generarle a la Corte incentivos a ser deferente con el decisor primario. ${ }^{132}$ Sin embargo, según hemos venido

${ }^{130}$ La frase es de la juez D.P. Wood, "Generalist Judges in a Specialised World”, SMU Law Review 59 (1997): 1756.

${ }^{131}$ La circunstancia de que la Corte Suprema estructure el conocimiento de sus asuntos sobre la base de "salas especializadas" (política implementada desde 1995 y que la organiza en asuntos civiles, penales, constitucionales y laborales) no altera la conclusión de que sean jueces "generalistas" en el sentido definido en este trabajo, pues no es condición para el desempeño de ellas la especialización en los asuntos que deben resolver.

132 De hecho, esto es lo que ocurre en algunas materias, como la regulación eléctrica. En materia sancionatoria es común que la Corte actúe deferentemente con la SEC y confirme sus asertos. Una simple constatación numérica simple (y por cierto incompleta) confirma este aserto: de los 65 casos fallados en el período 2010-2015, los revocados por la Corte Suprema fueron sólo 14, sobre la base fundamentalmente — salvo un par de excepciones - de la teoría del decaimiento del procedimiento administrativo (sobre este último, véase E. Evans \& D. Poblete, “¿Prescripción o decaimiento del procedimiento administrativo sancionador?: El caso de la industria eléctrica", en Sanciones administrativas, editado por J. Arancibia \& P. Alarcón (Santiago: Thomson Reuters, 2014), 217 y ss.). 
argumentando, la concreción práctica de dicho incentivo dependerá fundamentalmente de los recursos a través de los cuales la decisión llega a su conocimiento. ${ }^{133}$ En materia de libre competencia, las decisiones son revisadas por la Corte Suprema a través del llamado "recurso de reclamación" (artículo $27^{\circ}$ del DL 211). En materia medioambiental, el recurso aplicable es el de casación. Las diferencias hasta aquí descritas en uno y otro sistema son resumidas en el siguiente cuadro:

\section{Cuadro 1. SISTEMAS DE LIBRE COMPETENCIA Y MEDIOAMBIENTE EN CHILE}

\begin{tabular}{lll}
\hline & Libre competencia & Medioambiente \\
\hline Naturaleza del sistema & Acusatorio & Inquisitivo \\
Modelo de decisión de la agencia & Implementación & Adjudicación \\
Recurso ante la Corte Suprema & Reclamación & Casación \\
Revisión por la Corte Suprema & Plena & De derecho, restringida \\
\hline
\end{tabular}

En materia de protección de la libre competencia, el sistema legal de escrutinio de las decisiones adoptadas por el TDLC es amplio y ambiguo. El recurso de reclamación es, en sí, extraño en un contexto supuestamente jurisdiccional, pues la reclamación tiene como ámbito propio el administrativo. ${ }^{134}$ Por lo mismo, el alcance de este "recurso" es indefinido a nivel teórico, ni tampoco fue acotado en la ley. Esto lo vuelve una herramienta procesal extremadamente abierta, que confiere un amplio margen para la determinación judicial. De hecho, la propia Corte ha llegado a interpretar que el recurso le confiere la facultad de revisar cuestiones de derecho, de política y de hechos. ${ }^{135} \mathrm{Y}$ la evidencia

${ }^{133}$ Ver sección 2.3 .

134 Así lo hizo notar la propia Corte Suprema durante la tramitación del proyecto de ley que creó el TDLC: "la denominación de reclamación es ajena al sistema de recursos procesales ante los tribunales de justicia y más bien se reserva al ámbito administrativo. Sería más propio establecerlo como recurso de casación" (véase Historia de la Ley $N^{\circ}$ 19.911, 35-6).

135 Por ejemplo, comentando acerca de la naturaleza del recurso de reclamación, la Corte ha señalado que tiene una plena jurisdicción que le permite revisar todos los aspectos considerados por el TDLC, "incluyendo el análisis económico y legal que le permitió alcanzar la su decisión" (Corte Suprema, Consulta de Subtel sobre participación de concesionarios de telefonía móvil en concurso público de telefonía móvil digital avanzada, Rol 4797-2008, sentencia del 27 de enero de 2009, C. $\left.6^{\circ}\right)$. 
empírica permite confirmar esta afirmación. Aunque cuantitativamente muchas de las decisiones del TDLC han sido reafirmadas por la Corte, el análisis cualitativo muestra que, en la práctica, el recurso funciona de manera "plástica", moldeable a la sola voluntad de la Corte, dependiendo del tipo y características del caso concreto. En buena parte de las ocasiones, ha funcionado casi como una verdadera apelación, en los términos más amplios posibles, permitiendo la revisión de aspectos vinculados al derecho, los hechos e incluso la política. ${ }^{136}$ Aunque en muchas ocasiones la Corte ha alcanzado resultados sustantivos correctos, en ocasiones ha sustituido el razonamiento del TDLC por el suyo propio en cuestiones altamente técnicas. ${ }^{137}$ De este modo, producto de un cuestionable diseño del sistema de recursos que no toma en cuenta las características del revisor, impera en el análisis una ausencia de deferencia que, utilizando la terminología introducida anteriormente, bordea la interferencia. ${ }^{138}$

Por razones diversas, pero igualmente vinculadas al diseño institucional, la Corte Suprema también ha actuado con ausencia de deferencia en materia medioambiental. En esta materia, dado el carácter revisor/adjudicador de los TMA, el legislador consagró un sistema que en principio debía restringir las actuaciones de la Corte Suprema, la cual sólo conocería de los aspectos de derecho de un asunto por la vía del recurso de casación. Desde la perspectiva del diseño institucional, entonces, el sistema fue creado de manera teóricamente correcta, considerando las características de especialización de los organismos de-

${ }^{136}$ Esto se manifiesta también en aspectos procesales. La Corte ha estimado admisibles recursos de hecho en contra de resoluciones del TDLC que declaran inadmisibles apelaciones, pese a que este recurso está regulado en el Código de Procedimiento Civil exclusivamente para la apelación.

${ }^{137}$ El caso más relevante es James Hardie (2003), donde la corte sostuvo un enfoque textualista del artículo 3 letra c) del DL 211 y definió erróneamente los precios predatorios (véase Corte Suprema, Producción Química y Electrónica Quimel S.A. contra James Hardie Fibrocementos Limitada, Rol 3449-2006, sentencia del 29 de noviembre de 2002).

138 Esto es, además de lo explicado en el texto principal, un reflejo del deficiente diseño orgánico del sistema de competencia chileno, que pone a la Corte Suprema en una posición de superior jerárquico inmediatamente superior al decisor primario, transformándola en una verdadera segunda instancia. Aspectos relativos a celeridad procesal pueden explicar esta anomalía. 
cisores y revisores y los incentivos que acarreaba el adoptar un sistema recursivo más amplio para llegar a la Corte Suprema.

Lo que el diseño no previó (o no pudo evitar) fue el influjo de un aspecto institucional particular del derecho chileno, de carácter general y no solamente vinculado al ámbito medioambiental: la forma cómo se ha tratado jurisprudencialmente el llamado "recurso de protección". Se trata éste de una acción constitucional de amparo, especialmente diseñada para la protección de garantías establecidas en la propia Constitución, cuya naturaleza es cautelar, de urgencia, que se tramita sin forma de juicio y cuyo fallo, atendida su lógica de funcionamiento, no genera el efecto de cosa juzgada. ${ }^{139}$ No obstante, en la práctica la Corte Suprema ha comenzado a utilizar este recurso como una acción de nulidad ordinaria de actos administrativos; esto es, como un verdadero contencioso sin forma de juicio. ${ }^{140}$ La razón es atendible: no existe en nuestra legislación otro medio que pueda ser utilizado con la misma finalidad, dada la falta de un contencioso administrativo. ${ }^{141}$ El recurso de protección, entonces, se ha transformado de facto en el verdadero contencioso-administrativo del sistema chileno.

El efecto del recurso de protección en la ausencia de deferencia proviene del hecho de que uno de los derechos susceptibles de protección a través del uso de esta acción constitucional es el "derecho a vivir en un

${ }^{139}$ El artículo 20 inciso primero de la Constitución chilena indica que "el que por causa de actos u omisiones arbitrarios o ilegales sufra de privación, perturbación o amenaza en el legítimo ejercicio de los derechos y garantías establecidos en el artículo 19, números [...] podrá ocurrir por sí o por cualquiera a su nombre, a la Corte de Apelaciones respectiva, la que adoptará de inmediato las providencias que juzgue necesarias para restablecer el imperio del derecho y asegurar la debida protección del afectado, sin perjuicio de los demás derechos que pueda hacer valer ante la autoridad o los tribunales correspondientes". Véase A. Bordalí, "El recurso de protección entre exigencias de urgencia y seguridad jurídica", Revista de Derecho 19 (2006): 205-228; G. Gómez Bernales, Derechos fundamentales y recurso de protección (Santiago: Ediciones UDP, 2005), 19-20; Mosquera \& Maturana, Los recursos procesales, 411-434 (ver nota 85 ).

${ }^{140}$ La doctrina chilena se ha mostrado crecientemente preocupada por esta tendencia. Por ejemplo, A. Vergara, "Esquema del contencioso administrativo: su tendencia hacia un modelo mixto y situación actual del recurso de protección", en Litigación pública, editado por J. Arancibia, J.I. Martínez \& A. Romero (Santiago: Thomson Reuters, 2011), 37-63.

141 Ver sección 3.1.1. 
ambiente libre de contaminación". ${ }^{142}$ Invocando a este último, la acción de protección ha sido utilizada para solicitar (y en algunos casos decretar) la nulidad de Resoluciones de Calificación Ambiental, que en términos generales constituye el acto administrativo final a través del cual se establecen las condiciones o exigencias que deberán cumplirse para ejecutar un determinado proyecto o actividad. ${ }^{143}$ Este uso implica, en los hechos, conferir un efecto de validez general a una sentencia cuyo objeto es, jurídicamente, de tutela transitoria. En la práctica, entonces, con un régimen medioambiental al cual se superpone el sistema constitucional de protección, que controla escasamente el actuar del órgano generalista, al considerar la invalidez de los actos administrativos la Corte opera bajo una lógica de protección de garantías, que le permite conocer, de manera muy rápida (!), cuestiones de hecho, derecho o política. ${ }^{144}$

Recapitulando, entonces, es posible constatar una falta de deferencia importante en el trato que confiere la Corte Suprema en materia de libre competencia y medioambiental. Notablemente, esta constatación

${ }^{142}$ Artículo 19 N. ${ }^{\circ} 8$ de la Constitución chilena. El recurso de protección, en este caso, sólo se permite en contra de un "acto u omisión ilegal" (no uno arbitrario) "imputable a una persona determinada" (artículo 20 inciso segundo de la Constitución chilena).

${ }^{143}$ Artículo 25 de la Ley de Bases General del Medio Ambiente.

144 Desde el año 2009 la Corte Suprema ha utilizado un control procedimental intenso en materia de revisión judicial de decisiones administrativas ambientales. Aunque en principio esto podría ser entendido como una cuestión de deferencia, lo cierto es que al utilizar el recurso de protección su razonamiento se vuelve contingente, carece de estabilidad y es fácilmente sustituible por la tutela de derechos fundamentales, lo que hace desaparecer los efectos de la deferencia. Por cierto, reiteramos, esto no es sino la reproducción de lo que sucede en otros sectores del derecho chileno con dicha acción. Véase, por ejemplo, J.C. Ferrada, "El recurso", 151 y 152 (ver nota 100); J.C. Ferrada, A. Bordalí \& K. Cazor, "El amparo constitucional contra los actos de la administración del Estado en Iberoamérica: un análisis comparado con el recurso de protección chileno", Revista Ius et Praxis 10, n. ${ }^{\circ} 2$ (2004): 9; L. Cordero Vega, "Los límites de la jurisprudencia administrativa y las fuentes del derecho administrativo. Las consecuencias del caso de la Municipalidad de Zapallar", Revista de Derecho Administrativo 7 (2012). En general, mediante sentencias declarativas (e incluso constitutivas de derechos) dictadas en sede de protección, procedimientos de urgencia han dado lugar a medidas anticipativas que se consolidan en una sentencia que, aunque no da lugar al efecto de cosa juzgada material, sí suele operar como una sentencia firme estimatoria. Véase, en este último sentido, J.C. Marín, Las medidas cautelares en el proceso civil chileno. Doctrina, jurisprudencia y derecho comparado (Santiago: Editorial Jurídica, 2004), 212 y 213. 
va en contra de sus propias declaraciones sosteniendo que su rol es el de un tribunal de casación. ${ }^{145}$ Como hemos expresado, una explicación práctica de dicho fenómeno dice relación con el diseño institucional, el cual le confiere espacios suficientes para actuar de dicho modo. Sin embargo, la explicación parece ir más allá. Existen plausibles fundamentos para estimar que la razón radica en el hecho de que la Corte "desconfía" de los organismos especializados ${ }^{146}$ y pareciera confundir la necesidad de reforzar su control jerárquico sobre estos últimos con una supuesta demanda por una revisión más intrusiva. Esto es, a nuestro juicio, un error. Una menor deferencia no implica una menor vigilancia ni una disminución de la capacidad de controlar los eventuales comportamientos abiertamente transgresores de estos tribunales. Con todo, nuestro argumento central es que, sin perjuicio de las razones subyacentes a una mayor intervención, el diseño institucional debiera moldear la actuación del órgano revisor a sus propias características institucionales.

\subsubsection{Algunos de los peligros que plantea el diseño institucional vigente y su posible solución}

La actual desvinculación existente entre la variable institucional de especialización/generalidad y la variable relativa al estándar de revisión tiene consecuencias importantes para los sistemas de libre competencia y medio ambiente chilenos. En la práctica, ello ha implicado que la relación entre el órgano revisor y el decisor no pueda calificarse de "armónica" sino — en buena medida — de "antagónica" (en la terminología que hemos utilizado anteriormente). ${ }^{147}$ La pregunta central es si esto está de acuerdo con las bases del sistema legal chileno. La respuesta, a

145 Por ejemplo, al informar sobre el proyecto de ley que creó los TMA, la Corte indicó expresamente que "cabe reiterar la preocupación que, al informarse otros proyectos de similar contenido, ha expresado esta Corte Suprema acerca de la proliferación de recursos sobre materias especiales que, en número creciente, engrosan la heterogénea y sobreabundante competencia que el ordenamiento le ha venido asignando, en desmedro de su calidad de Tribunal de Casación que naturalmente le corresponde dentro de nuestro sistema jurídico" (Historia de la Ley $\left.N^{o} 20.600,42\right)$.

146 Por ejemplo, en materia de libre competencia, algunos fallos parecen indicar una cierta aprensión ante los aparentes "excesos" del uso del análisis económico (en lugar de los tradicionales silogismos legales).

${ }^{147}$ Ver sección 2.3.2. 
nuestro juicio, es negativa. Sin entrar a juzgar la conveniencia de un sistema de tribunales especializados, lo cierto es que existen una serie de mecanismos insertos en nuestro diseño institucional y otros sustantivos que aseguran que este tipo de tribunales permanezcan adecuadamente restringidos, incluso si la Corte actúa de una forma más deferente. Entre ellos está, por ejemplo, el respecto al principio de proporcionalidad. ${ }^{148}$ Por el contrario, la relación hasta cierto punto antagónica que se ha dado hasta ahora entre revisor y decisor, producto de la ausencia de deferencia, acarrea una serie de riesgos institucionales en materia de revisión y perversos incentivos para los usuarios de ambos sistemas analizados.

En primer término, se incentiva a las partes a hacer un uso intensivo o estratégico de los recursos, pues ellos en la práctica operan como un verdadero recurso jerárquico. En materia de competencia, esta razón (sumado al hecho que el TDLC ha emitido más decisiones relevantes que sus predecesores) explica el incremento de la participación de la Corte Suprema en el litigio de competencia desde la entrada en vigencia de la nueva institucionalidad en el año $2004 .{ }^{149}$ En materia medioambiental, la acción de protección ha sido intensamente utilizada, en comparación a la presentación de sólo unos cuantos recursos de casación. ${ }^{150}$ En este último ámbito, se suma además la posibilidad de que las partes estén dando un uso estratégico al primero de los recursos mencionados, produciéndose lo que la literatura denomina "fórum shopping": el uso

${ }^{148}$ El análisis de estos resguardos institucionales excede los límites autoimpuestos en este trabajo.

149 Según nuestro conocimiento, desde la creación del TDLC y hasta el mes de marzo de 2015, se han interpuesto 103 recursos de reclamación, 90 de ellos en causas contenciosas y 13 de ellos en causas no contenciosas. La Corte Suprema se ha pronunciado sobre ellos en 90 oportunidades, confirmando total o parcialmente la resolución recurrida en 75 casos y revocando total o parcialmente en los 15 casos restantes. Adicionalmente 3 procesos fueron conciliados una vez deducido el recurso de reclamación. En la actualidad la Corte Suprema está conociendo 10 recursos de reclamación por causas de libre competencia, 7 de ellos interpuestos en procesos contenciosos y los 3 restantes en procesos no contenciosos.

${ }^{150}$ Según nuestro conocimiento, a marzo de 2015 se han interpuesto 11 recursos de casación en contra de sentencias pronunciadas por el Segundo y el Tercer Tribunales Ambientales, encontrándose 8 de dichos procesos pendientes ante la Corte Suprema. En los tres casos en los que la Corte Suprema se ha pronunciado ha anulado la resolución recurrida, ya sea acogiendo el recurso de casación o anulando de oficio. 
del ámbito procesal que aparezca como más conveniente a los intereses de quien lo utiliza. ${ }^{151}$

En segundo término, existe la posibilidad de que se produzca una selección de estándares ad-hoc, ya sea al caso concreto o al tipo de materia. El problema se acrecienta por la ausencia en Chile de uno de los elementos esenciales que permiten que las doctrinas judiciales posean cierta lógica y coherencia: el respeto y confianza en los precedentes (lo que la doctrina anglosajona denomina stare decisis). En materia medioambiental, por ejemplo, existen atendibles razones para pensar que el mismo estándar amplio usado en materia de vulneración de derechos fundamentales está siendo utilizado en la revisión de las actuaciones de los TMA, aun cuando el legislador haya optado por intentar acotar esta última. Resulta al menos plausible considerar que más allá de las diferencias entre la diversa naturaleza de los recursos, ellos serán eventualmente considerados bajo un prisma similar.

Tercero, dado el carácter generalista de la Corte, existe el peligro de que se cometan muchos errores en las decisiones. Si bien es cierto que el error decisional, sea del tipo I o del tipo II, es inevitable, hemos indicado que es precisamente ésta una de las razones más utilizadas para crear especialización. ${ }^{152}$ El uso no deferente de los recursos elimina los beneficios de la especialización y, en última instancia, desvirtúa el sistema creado por el legislador. Un buen ejemplo lo provee el tratamiento que se ha dado a algunas conductas en materia de libre competencia. Tradicionalmente, el enfoque adoptado por la Corte en esta materia no ha estado dominado por las consideraciones de eficiencia que hoy resultan casi estándar a nivel mundial, sino por consideraciones vinculadas a la justicia redistributiva. De hecho, la Corte ha sostenido expresamente que la sanción debe estar inspirada en el principio de

${ }^{151}$ Así, la no-deferencia con que la Corte ha actuado en materia de recursos de protección puede proveer incentivos a quienes se oponen a un determinado proyecto, atendido los estándares garantistas bajo los cuales opera la decisión en este tipo de recursos. El desarrollador, en cambio, que desea obtener una suerte de "certificación" de que cada uno de los trámites y etapas del procedimiento administrativo se han cumplido fielmente y con apego a la legalidad, probablemente optará por la vía de los TMA, caso en el cual es altamente probable que el conflicto de todas formas termine siendo resuelto por la Corte Suprema.

152 Ver sección 2.1.2. 
culpabilidad, ${ }^{153}$ y que la conducta debe ser "reprochable", esto es, "un acto voluntario de naturaleza ilegal debido a su desacuerdo con las normas establecidas en la ley para la protección de la libertad que debe existir para competir en los mercados". ${ }^{154}$ Asimismo, el principio de proporcionalidad también ha jugado un rol muy relevante en la jurisprudencia de la Corte en esta materia. ${ }^{155}$ Con todo, hay signos positivos de un avance hacia una visión más económica, donde la Corte acepta una visión más consecuencialista basada en la disuasión y la eficiencia. ${ }^{156}$

Existen diversas formas de restringir estos peligros. Entre ellas, dos son las que han recibido mayor atención en el derecho nacional. Primero, podría intentarse un cambio en la estructura de los tribunales especializados, incorporando a un miembro de la Corte Suprema o, como alternativa de "segundo-mejor", de alguna Corte de Apelaciones dentro de la composición del tribunal, de modo que la revisión incorpore el pensamiento o política de derecho general de la Corte y exista, como contrapartida, un cierto grado de deferencia con las decisiones de un "par". Sin embargo, existen al menos tres objeciones a esta idea. La primera es práctica: la experiencia anterior en la Comisión Resolutiva (una de las antecesoras del TDLC), uno de cuyos miembros era precisamente un juez de la Corte Suprema, no fue altamente favorable. La segunda objeción está vinculada al problema "cultural" de que los jueces no son necesariamente deferentes con sus pares. Finalmente, la tercera objeción se relaciona con el problema jurídico antes señalado de que en Chile, en general, no es inusual que salas distintas de la misma Corte provean soluciones contradictorias (incluso ante problemas similares) debido al débil rol del precedente y la escasa aplicación del principio de igualdad.

Una segunda modificación institucional que se ha debatido para frenar los peligros del diseño actual dice relación con delimitar en la

153 Corte Suprema, FNE y Banco de Chile con Falabella y otros, Rol 23392008, sentencia del 13 de agosto del 2008, C. $17^{\circ}$.

154 Corte Suprema, Voissnet con Empresa de Telecomunicaciones de Chile S.A., Rol 6236-2006, sentencia del 4 de julio de 2007, C. $29^{\circ}$.

155 Corte Suprema, Demanda de OPS Ingeniería Ltda. y otros contra Telefónica Móviles de Chile S.A., Rol 8077-2009, sentencia del 7 de julio de 2010, C. $17^{\circ}$.

${ }^{156}$ Por ejemplo, Corte Suprema, FNE contra Compañia Chilena de Fósforos S.A., Rol 277-2010, sentencia del 2 de junio de 2010, C. $22^{\circ}$ (indicando que la multa debe imponer [al defendido] costos mayores al beneficio esperado por haber impuesto barreras artificiales de entrada al mercado). 
propia normativa el ámbito de los recursos. Una reforma en este sentido sería compatible con las recomendaciones teóricas de diseño que hemos mencionado en este trabajo. Más aún, existen precedentes que van en línea con esta propuesta. En materia de libre competencia, durante la tramitación de la reforma del año 2009 se intentó cambiar sin éxito el actual recurso de reclamación por uno de apelación. Esto sinceraría el estado de la cuestión, pero no resuelve el hecho que la Corte Suprema mantendría una jurisdicción amplia, de segunda instancia, sin ser éste su rol natural. En materia medioambiental, el problema recursivo detectado en libre competencia se trató de enmendar por la vía de dotar a la Corte Suprema de un recurso más acotado, el de casación. No obstante, existe poca experiencia en el uso de este mecanismo, pues el problema del recurso de protección no será solucionado a menos que se elimine la posibilidad de acudir por esta vía a la Corte, lo cual requiere una modificación constitucional en este sentido cuya conveniencia resulta altamente cuestionable y probablemente impracticable.

\section{CONCLUSIONES}

En este trabajo hemos argumentado que para que un sistema institucional pueda operar de una manera eficiente en un marco de legitimidad debe dar una respuesta unívoca a dos cuestiones que - lamentablemente; quizás por su diversa naturaleza (orgánica una, sustancial, la otra) - suelen ser resueltas de manera separada por los ordenamientos jurídicos y la literatura especializada: las características institucionales del órgano revisor de una decisión y el ámbito (o estándar) de revisión. Esa respuesta unívoca consiste en que, desde una perspectiva de buen diseño institucional, este último debiera ser creado "a la medida" de las primeras. Hemos, además, ejemplificado este problema en el derecho chileno, específicamente en materia de protección de la libre competencia y del medio ambiente, mostrando cómo en ambos casos, por diversas causas vinculadas a diseños particulares, el deficiente diseño institucional ha repercutido en las decisiones.

Existen numerosas preguntas relacionadas que han quedado inexploradas en este trabajo. Por ejemplo, nada hemos dicho sobre las ideas normativas que debieran subyacer a la creación de tribunales especializados, o qué modelo debieran seguir otras instituciones especializadas 
que sean diseñadas a futuro; tampoco hemos hecho referencia al plano positivo o empírico: qué tipo de estándares efectivamente están utilizando los revisores (principalmente las Cortes superiores) en nuestro derecho. De hecho, ni siquiera hemos pretendido efectuar un estudio acabado en materia de libre competencia y medio ambiente. La agenda en materia de derecho institucional en Chile y Latinoamérica se encuentra aún poco desarrollada, por lo que esperamos que las ideas aquí planteadas - una muy pequeña parte de todas las que pueden ser exploradas - puedan ser testeadas y expandidas en el futuro cercano. De este modo enriqueceremos nuestro entendimiento de la interpretación judicial, favoreceremos al debate permanente en el derecho público y, a través de él, contribuiremos a la mejora constante de las instituciones que permiten la buena gobernanza. EP 